\section{Propuesta metodológica para el desarrollo de la lectura fácil según el diseño centrado en el usuario}

\author{
Proposal for the development of \\ easy-to-read digital products according \\ to the user-centered design methodology
}

\section{Resumen}

Con la llegada de la lectura fácil (LF) al medio digital, los productos en LF entran en el ámbito de la interacción persona-ordenador. La comprensibilidad y la accesibilidad de los textos se amplían pues a la accesibilidad del medio. En este trabajo se estudia la afinidad entre la metodología del diseño centrado en el usuario (DCU) según ISO 924I-2 IO:20IO y la LF, a partir de su enfoque de participación del usuario. A través de los resultados de dos vertientes de trabajo, revisión documental y benchmarking empírico de una muestra significativa de proyectos de LF en distintos países, se analizó la proximidad de la LF al DCU desde el plano teórico y desde su práctica en proyectos. Del análisis se deduce que un apoyo consciente de la LF en la metodología DCU podría proporcionarle una base sólida para el desarrollo exitoso de productos digitales.

\section{Palabras clave}

Discapacidad cognitiva, lectura fácil, diseño centrado en el usuario, accesibilidad, norma ISO 924I210:2010.

\begin{abstract}
The arrival of easy-to-read digital products places this method in the field of human-computer interaction. As a consequence, the comprehensibility and accessibility of the texts expands beyond the content to the accessibility of the tool and the interaction. In this paper we study the affinity between the user-centered design methodology (UCD) according to ISO $924 \mathrm{I}-$ 2I0:20IO and the easy-to-read products, based on its user participation approach. Throught the results obtained by a two-way methodology, document review and empirical benchmarking of easy-to-read projects in different countries, the proximity of easy-to-read to the UCD principles was analyzed from the theoretical angle and from their practice in projects. The analysis shows that a conscious implementation of HCD principles and activities in the design of easy-to-read products would provide a solid foundation and support a successful development of digital products.
\end{abstract}

\section{Keywords}

Intellectual disability, user-centered design, easy-to-read, accessibility, 924I-2IO:20IO.

\section{Rocío Bernabé Caro}

$<$ rocio.bernabe@sdi-muenchen.de>

Universidad de Lenguas Aplicadas del SDI München

Para citar:

Bernabé, R. (2017): "Propuesta metodológica para el desarrollo de la lectura fácil según el diseño centrado en el usuario". Revista Española de Discapacidad, 5 (2): I9-5I.

Doi: <https://doi.org/IO. 5569/23405 I04.05.02.02>

Fecha de recepción: 05-OI-20I7 Fecha de aceptación: I 8-09-20I7 


\section{Introducción}

En la actual sociedad digital y del conocimiento, la comprensión y la producción de textos digitales son necesarias para el desarrollo personal y social. La información digital forma parte de la actividad cotidiana profesional y de ocio. La existencia de barreras de acceso a estos contenidos, ya sean técnicas, cognitivas o de usabilidad, pueden convertirse en factores de exclusión y de restricción en la participación, así como mermar las oportunidades laborales y afectar negativamente a la autonomía, el desarrollo personal y la autodeterminación.

Hoy día en España, las barreras relacionadas con la comprensión afectan a 268.633 personas con discapacidad intelectual o del desarrollo reconocidas (Imserso, 20 I 5: I3). En países desarrollados, se estima que la cifra alcanza el i \% de la población y, en los menos desarrollados, hasta el $3 \%$, es decir, unos 200 millones de personas (Olimpiadas Especiales, 20I6). A estas cifras se suman las de otros perfiles como, por ejemplo, personas de edad avanzada, inmigrantes, turistas, personas con problemas de lectoescritura y aquellas con baja alfabetización. En suma, un amplio rango de perfiles en torno a un tipo de accesibilidad, la cognitiva, que está menos desarrollada (FEAPS Madrid, 20I4: I2), muy estigmatizada, que posee una alta complejidad y que requiere acercamientos multidisciplinares (Scior et al., 20I5: I).

El término discapacidad intelectual (DI) refleja la naturaleza del concepto subyacente, cuya definición constitutiva permite entenderla según apuntan Verdugo y Schalock (20I0: I2):

- En términos de limitaciones en el funcionamiento humano.

- Entendiendo la discapacidad desde una perspectiva multidimensional y socioecológica.

- Ligada a la importancia del uso de apoyos individualizados en la mejora del funcionamiento humano.

El enfoque multidimensional se basa en el modelo actual del funcionamiento humano y sus cinco dimensiones, cuya interacción influye de forma directa en el estado de discapacidad de cada persona en su contexto determinado. Como se observa en la figura del modelo, los apoyos desempeñan una función determinante a la hora de compensar o reducir el estado de discapacidad.

\section{Figura 1. Modelo multidimensional del funcionamiento humano}

I. HABILIDADES INTELECTUALES

II. CONDUCTA ADAPTIVA

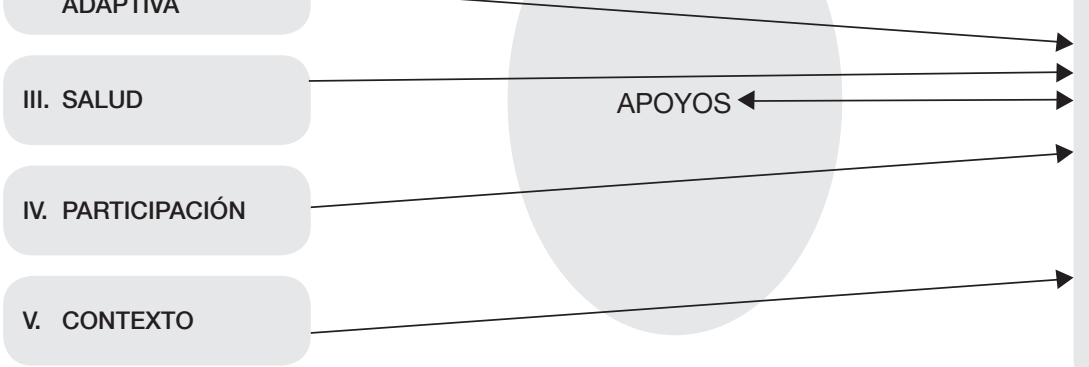

Fuente: Wehmeyer et al. (2008: 7). 
Los apoyos son estrategias y recursos para promover el desarrollo, la educación, los intereses y el bienestar personal, así como para mejorar el funcionamiento individual (Verdugo y Schalock, 20I0: I7). Dependiendo de su naturaleza, los apoyos pueden ser servicios, productos, tecnología, procesos organizativos, etcétera, y persiguen servir de puente entre las habilidades de la persona y las exigencias provenientes del entorno. El modelo contempla, por tanto, que los estados de discapacidad pueden compensarse, al menos en parte, con ayudas.

Aldo Ocampo (2015: 7) menciona los avances conseguidos en el ámbito de la accesibilidad cognitiva y sus estrategias de éxito, entre los que nombra los grandes esfuerzos de las personas afectadas e involucradas, el desarrollo del marco legal, la progresiva dedicación de recursos, el desarrollo tecnológico y la metodología de la lectura fácil.

Precisamente en esta búsqueda e implementación de apoyos que acerquen a todas las personas al entorno se enmarca el presente trabajo. En concreto, en el análisis de las metodologías de la LF y del DCU. Es decir, de una metodología que busca la accesibilidad en la comprensión y de otra que la persigue en la interacción personaordenador. Al estar centradas en el usuario, se presume una afinidad notable en sus actividades y principios.

\section{La lectura fácil y el diseño centrado en el usuario como estrategias transversales de apoyo}

\subsection{La lectura fácil}

La LF es un planteamiento metodológico general para volver accesible la información y facilitar la comprensión de los mensajes escritos a todas las personas, en su diversidad intelectual y de aprendizaje (Vived y Molina, 20 I 2: 94). De este modo, se ubica dentro del principio de la accesibilidad universal de bienes, productos y servicios a las personas con discapacidad recogido en la legislación de nuestro país en el Real Decreto Legislativo por el que se aprueba el texto refundido de la Ley General de Derechos de las Personas con Discapacidad y de su Inclusión Social (OED, 2015).

Con la LF se crean textos fáciles de leer y de comprender. No se trata de traducciones ni simplificaciones, sino de adaptaciones que hacen más fácil la lectura y la comprensión. Para ello, se tienen en cuenta el contenido, el lenguaje, las ilustraciones y la maquetación (IFLA, 20I0: 7).

A pesar de ser una metodología sólida (Bredel y Maаß, 2016: Iо8), existen déficits identificados por distintos autores. Entre otros:

- Oferta insuficiente para el público joven y adulto, sobre todo, en materia de educación (Estruga, 20I 5; Vived y Molina, 20 2: 9).

- Público meta muy amplio y heterogéneo. Entre otros, personas con discapacidad intelectual; con enfermedades y trastornos mentales y del comportamiento; con dificultades en el lenguaje por discapacidad auditiva; con dificultades de comprensión lectora por circunstancias transitorias, incluidos los inmigrantes; con dificultades de lectoescritura por un bajo nivel de estudios o de alfabetización; con dificultades de lectocomprensión por la edad, y las personas que trabajan con beneficiarios de textos en LF.

- En la definición de los grupos meta para las adaptaciones, atención insuficiente a los conocimientos y experiencias previas, vocabulario, nivel de lectocomprensión e intención comunicativa (Fröhlich y Candussi, 2015).

- Falta de datos empíricos sobre la eficacia de la metodología (Bock y Lange, 2015).

- Mejora limitada de la comprensión inferencial (Fajardo et al., 2013: I7).

- Necesidad de personalización del nivel de lectura y de ayudas durante la lectura.

- Generar un sistema lingüístico que, por falta de datos empíricos, se restrinja a las 
personas con DI fomentando de forma involuntaria su exclusión en vez de su inclusión (Schädler y Reichstein, 20I 5 ).

- Integración de la multimodalidad como factor favorecedor de la comprensión.

- Falta de técnicas semiautomáticas o automáticas de asistencia a la adaptación (Vived y Molina, 20I 2: 262).

- Altos costes.

La entrada de la LF en el mundo digital puede contribuir a resolver estos déficits, siempre y cuando los productos de LF se diseñen de forma accesible y cumplan los requisitos de las normas de accesibilidad UNE I39802:20 I 2 y UNE I39803:2012. Estas normas, basadas en las pautas de accesibilidad del consorcio $\mathrm{W}_{3} \mathrm{C}$, Web Content Accessibility Guidelines 2.0 (WCAG 2.0), contemplan, sin embargo, solo ciertos aspectos de la accesibilidad cognitiva. De hecho, el grupo de trabajo del $\mathrm{W}_{3} \mathrm{C}$ Cognitive and Learning Disabilities Accessibility Task Force (Cognitive A I IY TF) tan solo ha publicado hasta ahora un primer borrador con el título Cognitive Accessibility User Research en 2015. Más aún, según el mismo $\mathrm{W}_{3} \mathrm{C}$, las extensiones normativas de las WCAG 2.0 y el material de apoyo, incluidos los referentes a las personas con discapacidad cognitiva y de aprendizaje no se publicarán hasta 20I8 (Carreras, 20I5).

Independientemente de las normas, en el ámbito digital, el DCU ofrece a los productos digitales de LF una metodología de probada eficacia que tiene en cuenta la accesibilidad y al usuario, en su diversidad, a lo largo del diseño.

\subsection{El diseño centrado en el usuario}

El término diseño centrado en el usuario procede del inglés. Don Norman (2013) utilizó ya en I 988 el término user centered design en la primera edición de su libro The Design of Everyday Things, que es hoy día referente del DCU. Posteriormente, se acuñó el término buman centered design, que se utiliza en la actualidad.
La parte 2 Io de la norma ISO 924I (ISO, 2010), denominada Human-centered design for interactive systems, incluye una nota aclaratoria respecto a la terminología y subraya que el término human-centered design se usa en lugar de user-centered design con el fin de enfatizar que esta parte de la norma ISO 924 I también considera el impacto sobre y de una serie de partes interesadas o afectadas (en inglés, stakeholders) y, por tanto, no solo de aquellos que suelen identificarse como usuarios finales. No obstante, en la práctica, ambos términos se usan con frecuencia como sinónimos.

El propio Don Norman (2013: I6) menciona en el prefacio de la edición revisada de su libro Design of Everyday Things que el término buman centered design en sí no existía cuando se publicó la primera edición y, sin embargo, se hacía continuamente alusión a él.

En este trabajo se usa la denominación diseño centrado en usuario. Asimismo, el término "usuario" abarca a todas las personas que afectan o están afectadas por el diseño, ya sean usuarios finales o partes interesadas.

Atendiendo a la definición de la parte 2 ro de la norma ISO 924I (ISO, 20IO):

El diseño centrado en el usuario es un enfoque de desarrollo y diseño de sistemas informáticos que persigue hacer los sistemas interactivos más usables y útiles mediante un enfoque centrado en los usuarios, sus requisitos y necesidades, así como mediante la aplicación del conocimiento y técnicas de usabilidad, y de la ergonomía o factores humanos. Este enfoque favorece la eficacia, la eficiencia y mejora el bienestar humano, la satisfacción del usuario, la accesibilidad y la sostenibilidad. Del mismo modo, contrarresta posibles efectos adversos del uso en la salud humana, la seguridad y el rendimiento.

Según Don Norman (2013: 9), el DCU es una filosofía de diseño que incluye procedimientos destinados a que los productos satisfagan las necesidades y se adapten a las capacidades y las habilidades de la audiencia meta. La persona, 
sus capacidades y la tarea son objetivo final y prioritario frente a la funcionalidad. De este modo, el DCU es una metodología coherente con el concepto de apoyo.

Resumiendo, el acceso a la información desde la comprensión y el diseño es fundamental para defender los derechos básicos de decisión, autonomía y autodeterminación de las personas. Desde el punto de vista de la comprensión, la lectura fácil ofrece una solución eficaz (García, 20I2: 66) para salvar la brecha de comprensión entre el mensaje y el usuario. Desde el punto de vista del diseño digital, el DCU facilita la comprensión del sistema y posibilita experiencias satisfactorias al tener en cuenta los procesos cognitivos y mentales.

Al tratarse de dos metodologías preocupadas por satisfacer las necesidades de las personas y adaptar los productos a sus capacidades y habilidades, se estudia a continuación la presencia de esa afinidad en la teoría, a través de la revisión documental, así como en la práctica, a través del análisis de I 4 proyectos de LF en el ámbito digital.

\section{Objetivos y metodología}

El objetivo general planteado es observar la afinidad entre la metodología de lectura fácil y del diseño centrado en el usuario a partir del conocimiento disponible, así como explorar en qué medida proyectos actuales de lectura fácil incluyen ya actividades centradas en el usuario según el enfoque del DCU.

Este objetivo sustenta la hipótesis de partida de que las metodologías de la LF y del DCU son afines, ya que su foco de atención es el usuario, que se entiende más allá del usuario final. Dado que el DCU es una metodología muy probada y desarrollada, la LF podría beneficiarse de la sinergia de un acercamiento deliberado. Asimismo, y dado el enfoque iterativo y participativo del DCU, este método podría contribuir a generar datos empíricos sobre la eficacia de los productos y a una mejor definición de los grupos meta, dos aspectos ya identificados como insuficientes.

Para alcanzar el objetivo general, se han establecido los siguientes objetivos específicos:

I. Identificar afinidades entre la metodología de la LF y del DCU mediante el análisis de una muestra de publicaciones internacionales de organizaciones y autores de referencia en LF, a la luz de los principios básicos del DCU.

2. Analizar prácticas actuales en proyectos de LF en distintos ámbitos y países desde el punto de vista de la participación del usuario en las actividades realizadas en cada fase del ciclo de vida de un proyecto.

3. Recopilar buenas prácticas según el objetivo general del estudio.

Contribuir a deshacer el estigma en torno a la accesibilidad cognitiva destacando el valor general de estos productos para otros grupos diversos, más allá de las personas con discapacidad intelectual. Este objetivo se considera transversal, por lo que no se le aplica una metodología específica.

El procedimiento elegido para alcanzar los objetivos es mixto y combina la recopilación y el análisis de fuentes secundarias, y la generación y el análisis de datos empíricos. Las técnicas utilizadas son:

- Revisión documental de fuentes secundarias del conocimiento disponible de distintos países para inferir la proximidad entre la LF y el DCU. La comparación se realiza atendiendo a los principios del DCU según la norma ISO 924I:210:20IO.

- Benchmarking o análisis comparativo conforme a los objetivos mediante:

- Recogida empírica de datos correspondientes a una muestra de I4 proyectos de lectura fácil en seis ámbitos y de seis países de nuestro entorno, mediante un 
Figura 2. Esquema $A B C$ de las vertientes de la investigación

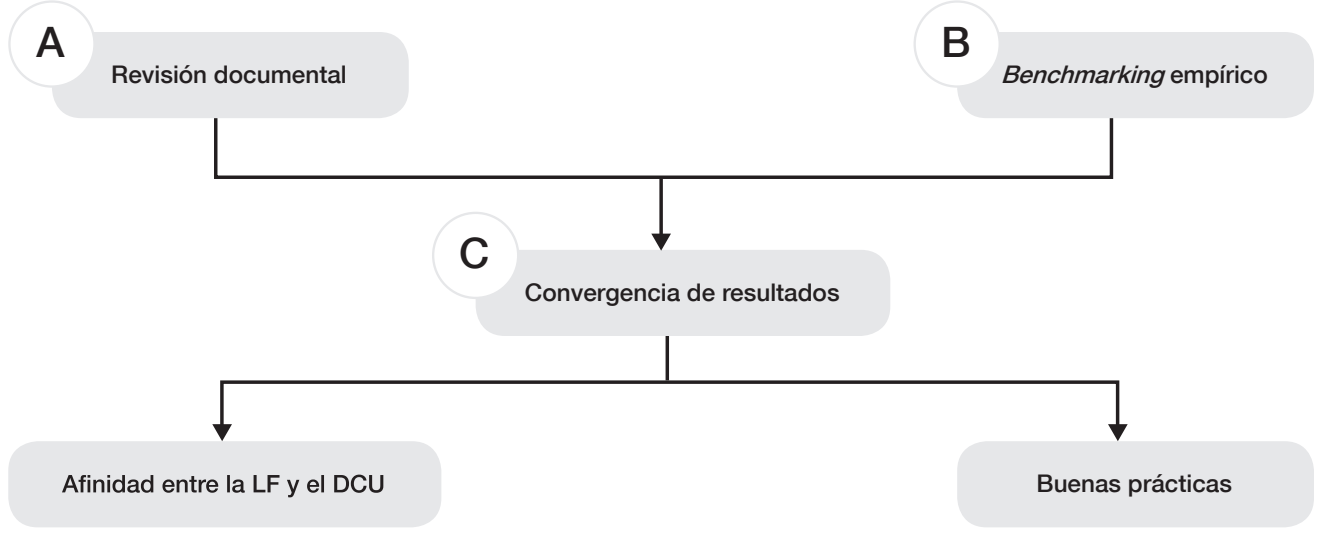

Fuente: elaboración propia.

cuestionario propio diseñado según las actividades del informe técnico ISO/

TR I 8529:2000.

- Análisis de actuaciones e identificación de buenas prácticas según el objetivo de estudio.

La combinación de ambas técnicas pretende observar afinidades en la teoría e identificar su grado de implantación en proyectos. La Figura 2 ilustra el proceso en sus tres vertientes de investigación A y B, y la C de convergencia de resultados.

\subsection{Revisión documental}

En esta vertiente se recurre al análisis de fuentes secundarias como técnica de investigación, es decir, a aquella que según Cea D’Ancona “[...] se limita al análisis de datos recabados por otros investigadores, con anterioridad al momento de la investigación” (Batthyány et al., 20I I: 86).

La búsqueda de las publicaciones se realizó en varias etapas. En un primer paso de búsqueda de documentos fuente, se utilizó Internet como instrumento de recopilación de datos a través de los siguientes recursos:
- Páginas web de instituciones, organizaciones, asociaciones, universidades y organismos públicos.

- $\quad$ Base de datos de la Universidad de La Rioja.

- Buscador académico Google Scholar.

Las principales palabras clave utilizadas fueron:

- Lectura fácil, participación del usuario, centrado en el usuario, reglas, pautas y proceso.

- $\quad$ Easy-to-read, user centered, process, guidelines.

- Leichte Sprache, benutzerorientiert, nutzerorientiert, Regeln, Prozess.

En el segundo paso, de contraste y selección de las fuentes, se aplicaron los siguientes criterios:

- Actualidad y validez de la información.

- Referencia a la LF como metodología de adaptación (IFLA o Inclusion Europe).

- Referencia a la LF como proceso que incluye al usuario.

- Accesibilidad de los documentos.

- Idioma. 


\begin{tabular}{|c|c|c|}
\hline Código ${ }^{1}$ & Título de la publicación & $\begin{array}{l}\text { Año de } \\
\text { publicación }\end{array}$ \\
\hline AIWG & $\begin{array}{l}\text { Make it easy: A guide to preparing easy-to-read information } \\
\text { (AIWG, 2011) }\end{array}$ & 2011 \\
\hline CHANGE & $\begin{array}{l}\text { How to make information accessible } \\
\text { (Change, 2015) }\end{array}$ & 2015 \\
\hline FEAPS & $\begin{array}{l}\text { Accesibilidad cognitiva. Guía de recomendaciones } \\
\text { (Feaps Madrid, 2014) }\end{array}$ & 2014 \\
\hline GBDS & $\begin{array}{l}\text { Making written information easier to understand for people with learning } \\
\text { disabilities. Guidance for people who commission or produce Easy Read } \\
\text { information } \\
\text { (Reino Unido, Departamento de Salud, 2010) }\end{array}$ & 2010 \\
\hline GBOCD & $\begin{array}{l}\text { Five principles for producing better information for disabled people } \\
\text { (Reino Unido, Oficina de Asuntos sobre Discapacidad, 2007) }\end{array}$ & 2007 \\
\hline IFLA & $\begin{array}{l}\text { Directrices para materiales de Lectura Fácil } \\
\text { (IFLA, 2010) }\end{array}$ & 2010 \\
\hline INCLEU & $\begin{array}{l}\text { Información para todos. Reglas europeas para hacer información fácil de leer y } \\
\text { comprender } \\
\text { (Inclusion Europe, 2009) }\end{array}$ & 2009 \\
\hline NETZWK & $\begin{array}{l}\text { Regeln für das Qualitäts-Siegel (Reglas para el sello de calidad) } \\
\text { (Netzwerk Leichte Sprache, 2014) }\end{array}$ & 2014 \\
\hline OGM & $\begin{array}{l}\text { Lectura fácil: métodos de redacción y evaluación } \\
\text { (García, 2012) }\end{array}$ & 2012 \\
\hline
\end{tabular}

Los elementos del corpus documental se recogen en la Tabla I, acompañados de un código para una referenciación posterior más sencilla y sin perjuicio de la entrada correspondiente en el apartado de bibliografía.

Las fuentes se estudiaron tomando de referencia los principios del DCU según la norma ISO 924I-210:2010. La valoración de la afinidad se guió por el recurso Lista de comprobación ${ }^{2}$ de la norma, pero adaptada al objetivo de estudio.

I. Código asignado para facilitar la identificación en las tablas de afinidades del capítulo de resultados.

2. La tabla original en inglés puede descargarse de: http://webdiis.unizar.es/asignaturas/IPO/wp-content/uploads/2OI3/o2/

Checklist-ISO-924I-2IO.pdf (acceso 8 de junio de 20I6).

\subsubsection{Principios de DCU según la norma ISO 9241-210:2010}

En este apartado se exponen de forma tabular los principios del DCU. Cada principio lleva asignado un código compuesto de la letra “p” mayúscula y el número del principio según aparece en la norma para facilitar su referenciación posterior en el texto o en los gráficos de los resultados. 


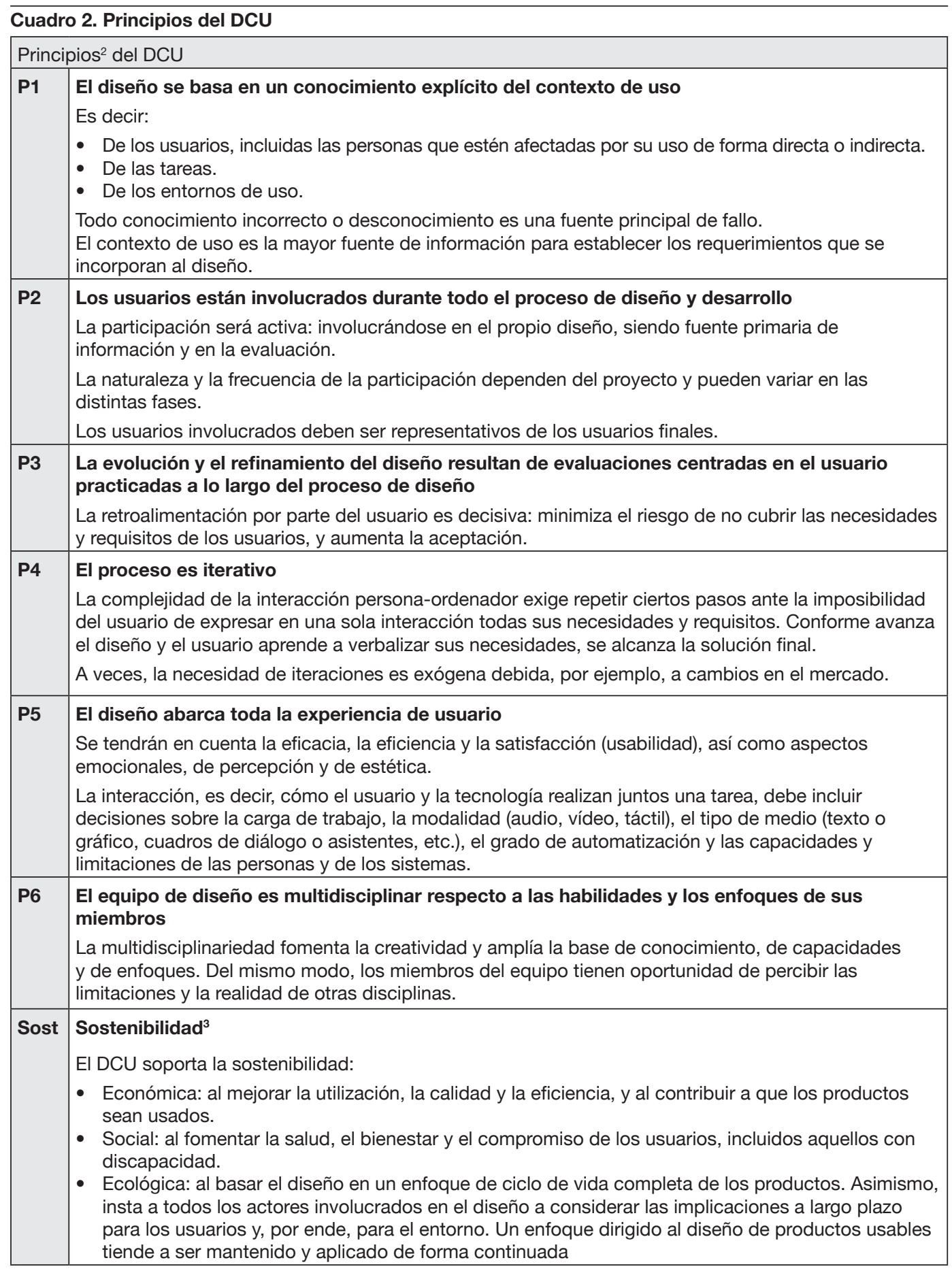

Fuente: ISO, 20IO.

3. Principios del diseño DCU recogidos en la norma ISO 924I-2 IO (ISO, 20IO).

4. A pesar de no ser un principio, la norma justifica su inclusión en su compromiso por crear normas para un mundo sostenible.

Con este fin, incorpora aspectos sociales, económicos y ecológicos en las normas. 
Una vez presentada la metodología de la vertiente $\mathrm{A}$, se describe la correspondiente a la vertiente $B$.

\subsection{Vertiente B. Benchmarking empírico de proyectos}

En esta parte del estudio se recurre al benchmarking como técnica utilizada principalmente en el mundo empresarial y que, en la actualidad, se aplica también en otros contextos como, por ejemplo, la investigación social y la educación.

Según el experto en marketing de contenidos Luis Maram (2013), el benchmarking se define como "un proceso sistemático y continuo para evaluar comparativamente productos, servicios y/o procesos de trabajo en organizaciones que evidencien las mejores prácticas sobre una área de interés, con el propósito de transferir el conocimiento de las mejores prácticas y su aplicación".

El benchmarking o análisis de la competencia realizado en este trabajo sigue el esquema propuesto por la empresa Alcoa (Boxwell, 2006: 2I). Al tratarse de un enfoque más general, le confiere una mayor aplicabilidad fuera de organizaciones empresariales y, por tanto, se ajusta más a los objetivos de la presente investigación.

El esquema siguiente, de elaboración propia, ilustra los seis pasos propuestos por Alcoa en forma de proceso lineal:

Figura 3. Pasos de benchmarking propuestos por la empresa Alcoa

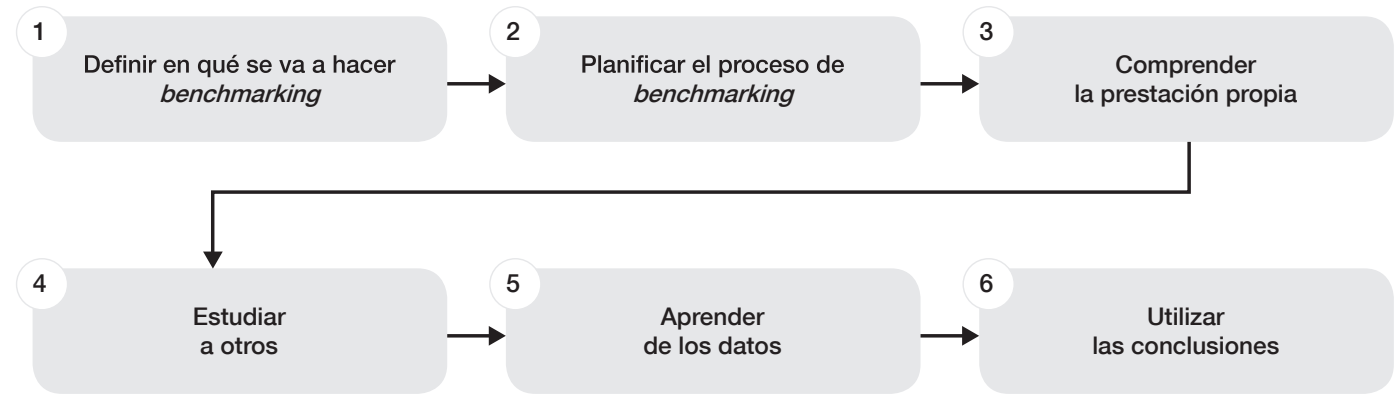

Fuente: elaboración propia. 
La aplicación del esquema se realizó siguiendo los siguientes pasos:

I. Benchmarking de la participación del usuario en el diseño de proyectos de LF. En los proyectos se tuvieron en cuenta las fases clásicas del ciclo de vida: concepción, planificación, desarrollo, evaluación, implementación y mantenimiento.

2. Selección de los proyectos según criterios de caracterización de la muestra:

- Ámbito de actuación dentro de la LF.

- Uso de tecnología.

- Idioma de trabajo.

- Diversidad geográfica de países participantes.

- Accesibilidad de las personas responsables del proyecto.

3. Uso de un cuestionario de elaboración propia ${ }^{5}$ como instrumento de recolección de datos.

4. Recogida de información sobre procesos o actividades con participación de los usuarios a lo largo del ciclo de vida del proyecto $^{6}$.

Los procesos y las actividades centrados en el usuario tomados como referencia son, por un lado, las cuatro actividades del DCU recogidas en la norma 924I-2IO:20IO y, en el caso de los procesos y actividades relativos al ciclo de vida, aquellos presentados en el informe técnico ISO/ $\mathrm{TR}^{7}$ I 8 529:2000, Ergonomía: ergonomía de la interacción persona-ordenador. Descripciones de los procesos de ciclo de vida centrados en el usuario (ISO, 2000).

\footnotetext{
5. Incluido en el Anexo I. De forma complementaria, se recurre a una entrevista informal por Skype y al correo electrónico como recursos tecnológicos de comunicación adicionales en los casos necesarios.

6. Aunque el término "usuario" incluye también a las partes interesadas o stakeholders (ISO, 2010), en el cuestionario se hace esta distinción para facilitar su entendimiento.

7. Los informes técnicos son por naturaleza informativos en su totalidad y no tienen que ser revisados hasta que los datos que proporcionan no se consideren válidos ni útiles (ISO, 200I). Este informe se creó a partir de encuestas de buenas prácticas en la industria y define toda una serie de "prácticas base" del DCU (Sánchez, 20II).
}

5. Extracción de conclusiones sobre el enfoque centrado en el usuario de los proyectos de LF analizados, así como de las prácticas detectadas.

De la muestra preseleccionada de 29 proyectos invitados a participar en el estudio, se obtuvo respuesta y disposición a participar de I4 proyectos. El Anexo II presenta los proyectos participantes en la vertiente $\mathrm{B}^{8}$ de benchmarking empírico. Los proyectos están ordenados por orden alfabético del ámbito de actuación.

La Figura 4 ilustra la distribución final por ámbitos. El ámbito de 'Tecnología, navegación en Internet y herramientas' fue el más representado, con un total de cuatro proyectos, seguido del ámbito de 'Actualidad y noticias' con tres proyectos. Los ámbitos 'Administración y asociaciones', 'Colecciones de libros digitales' y 'Educación e investigación’ están representados con un total de dos proyectos cada uno. El ámbito menos representado, con tan solo un proyecto, es el de 'Agencias de servicios de LF'.

\section{Resultados}

A continuación, se presentan los resultados de las vertientes teórica y empírica.

\subsection{Síntesis de los resultados de la revisión documental}

En la revisión documental se identificaron referencias a todos los principios del DCU y al concepto de sostenibilidad. La Figura 5 muestra el número de documentos con menciones.

8. En el Anexo III se presentan las asociaciones y proyectos de forma más detallada. 
Actualidad y noticias Administración y asociaciones

Agencias de servicios de LF

Colecciones de libros digitales

Educación e investigación

Tecnología, navegación en Internet y herramientas

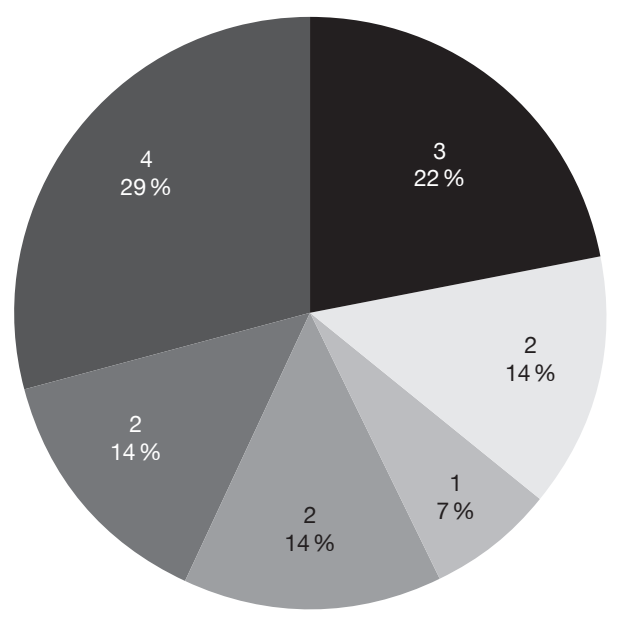

Fuente: elaboración propia.

\section{Figura 5. Documentos con referencias a los principios del DCU y a la sostenibilidad}

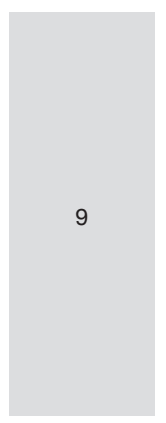

Principio 1



Principio 2

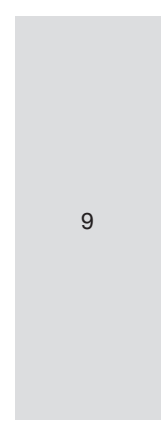

Principio 3

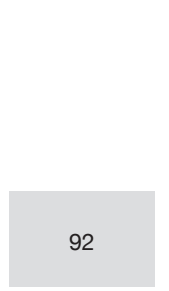

Principio 4

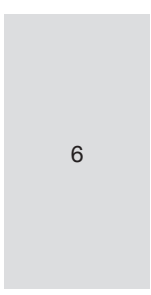

Principio 5

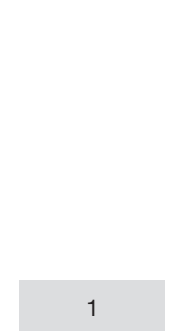

Principio 6

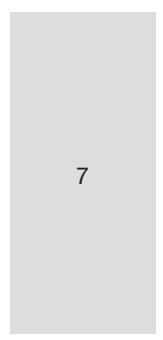

Sostenibilidad

Fuente: elaboración propia.

En el caso del principio I, sobre el conocimiento explícito del contexto de uso, el número de menciones es total respecto al conocimiento del usuario como usuario final y stakeholder. Asimismo, se ocupa de su desarrollo y se propone la creación de personas según Cooper.

El contexto de uso, determinante de la usabilidad y la accesibilidad en contextos digitales, requiere además un análisis específico de las tareas y de su realización, del reparto de funciones entre el sistema y el usuario, y de los factores del entorno de la interacción. Si bien las menciones son menores y, en parte, menos específicas, se subraya la necesidad de concretar las preferencias de los usuarios, por ejemplo respecto al formato y al medio de publicación, así como de identificar "las habilidades de la audiencia", "establecer posibles barreras" y "diseñar de forma accesible". 
El entorno, como parte del contexto de uso, también se referencia. En un caso se alude a la necesidad de adaptar el equipamiento y las aplicaciones a las necesidades de personas con discapacidades intelectuales, cognitivas o de otro tipo, de desarrollar interfaces adecuadas y de observar los estándares de accesibilidad web. El entorno social y cultural se menciona de forma más general mediante alusiones a la trascendencia de los textos, el tipo de formato y la participación activa de los usuarios.

La correspondencia con este principio es, por tanto, alta respecto a las necesidades y preferencias de los usuarios, pero menor respecto a las tareas y el entorno en sí.

En el caso del principio 2, sobre la participación activa en todo el proceso, se obtuvieron correspondencias en siete documentos, al excluirse dos casos que hacen referencia a su participación activa en fases concretas y no en general.

En los documentos, la participación se considera parte de la planificación, así como criterio de calidad y fuente de opinión experta, especialmente en la valoración de la comprensibilidad. En el caso de Feaps Madrid, el documento expresa su relevancia en todas las fases.

En cuanto a la participación de los usuarios, incluidos los stakeholders, en el documento de la IFLA se aluden a la importancia del contacto personal y la integración de los intermediarios para generar un interés activo y una actitud receptiva de la audiencia que contribuya a aumentar la aceptación de las publicaciones.

La afinidad en cuanto a la necesidad de involucrar de forma sistemática al usuario es, por tanto, alta. Del mismo modo, confluyen en el entendimiento sobre quién es el usuario, es decir, usuario final y stakeholder, y el valor de su contribución. No obstante, excepto en una publicación, no se expresa de forma generalizada la necesidad de la participación del usuario en otras fases distintas a las de la evaluación. En un caso se menciona su participación en las tareas de marketing previas a la creación.

En el caso del principio 3, sobre la evolución y el refinamiento del diseño mediante evaluaciones con los usuarios a lo largo del proceso de diseño, la correspondencia es muy elevada, con menciones en todos los documentos. Se identifican referencias directas a la necesidad de su planificación y de la evaluación de la comprensibilidad del texto a través de los mismos usuarios, ya que se consideran expertos y validadores últimos. La relevancia es tal que, como última instancia, cuando los usuarios no hayan podido participar en el proceso de creación, se estima necesario recoger su retroalimentación sobre la versión final.

Al tratarse de textos prescriptivos en su mayoría, las mismas pautas de redacción suponen un método eficaz y bien definido de evaluación. En el caso del libro de García (2012: 84-IO3), se le dedica un capítulo entero a este aspecto con propuestas exhaustivas desde el punto de vista de la redacción, la lecturabilidad, la legibilidad y la evaluación con usuarios, si bien en este último caso se apunta la ausencia de un método formal.

En el caso del principio 4, iteración, se identifican referencias en dos de las nueve publicaciones. No parece estar arraigado el concepto de iteración a lo largo de todo el diseño, si bien se subraya su importancia en dos de ellas. La ausencia de iteraciones sugiere que el proceso se considera principalmente secuencial con una o varias iteraciones al final en las fases de evaluación/validación por parte del usuario. En los documentos estudiados se considera necesario incluir las iteraciones en la planificación y, al mismo tiempo, se identifica una posible mayor duración de los proyectos a causa de las mismas.

En el caso del principio 5, experiencia de usuario, se identifican referencias en seis de las nueve publicaciones de la muestra. Aunque se trata de un concepto vinculado a formatos digitales, los documentos analizados incluyen aspectos que van más allá de la comprensibilidad de los textos, entre otras, las 
expectativas de los usuarios, las experiencias individuales y la imagen de la marca, donde algunos autores reconocen la importancia de los sellos y de explicitar la coautoría de las personas con discapacidad en las obras. En la muestra estudiada, la LF se vincula a grupos meta distintos, sin embargo, no se mencionan referencias sobre el papel de la LF en cada uno ellos, o bien sobre la afinidad o divergencia de sus expectativas.

Aunque en las publicaciones se incluyen los formatos digitales, tan solo se encontraron referencias concretas a la experiencia de usuario, a la usabilidad y a la accesibilidad en una de ellas.

En el caso del principio 6, equipo de diseño multidisciplinar, está referenciado solo explícitamente en una publicación. Necesita, pues, un estudio más profundo para establecer si el carácter multidisciplinar va más allá de la participación del usuario en las evaluaciones y abarca también, por ejemplo, los equipos de diseño o de mantenimiento, entre otros.

Por último, respecto a la sostenibilidad, aunque no se menciona como tal, en siete documentos aparecen referencias concretas a medidas o factores que la favorecen, como, por ejemplo: la fundamentación en principios, la descripción de flujos de trabajo y procesos para estandarizar las formas de actuación, su integración en procesos organizacionales superiores, la necesidad de una remuneración económica, así como la observación de la cadena de accesibilidad y la participación de todas las personas afectadas. En el caso de la administración, la publicación GBOCD especifica la necesidad de establecer de forma clara qué departamentos o personas son responsables de la provisión de información y, una vez definidas, la importancia de que estén incluidas en todos los procesos y ser conocidas por toda la organización.

A modo de conclusión, se identifica una afinidad media-alta de la LF con los principios del DCU. Respecto a los principios menos referenciados, más que incompatibilidad se observan posibles vías de actuación a la hora de afrontar los problemas mencionados en el apartado introductorio sobre lectura fácil.

\subsection{Síntesis de los resultados del benchmarking empírico}

En el ciclo de vida de los proyectos en LF analizados se observa un marcado enfoque centrado en el usuario de las actividades realizadas. En general, y de acuerdo con las respuestas recibidas, el usuario participa de forma activa en los proyectos, siendo las principales áreas de actuación la definición de requisitos, la evaluación y el marketing, mientras que resulta más moderada en las actividades de diseño y de mantenimiento.

En la primera fase, de concepción, se identifica una alta participación de los usuarios y una correspondencia casi completa con las actividades propuestas en el ciclo de vida recogido en el informe técnico ISO/TR I $8529: 2000$.

En la segunda fase, de planificación, la participación es igualmente alta. Es significativo para los proyectos el hecho de que los usuarios formen parte del equipo del proyecto, factor que es decisivo a la hora de velar por los intereses de los usuarios ante decisiones críticas, como se observa en el proyecto Tar Heel Reader. En relación con las actividades planificadas, su mayoría se ubica en la fase de desarrollo del producto, donde el usuario interviene en las tareas redaccionales y, especialmente, en la validación de los textos y de la herramienta. En las demás fases se detecta una menor participación, como también indica uno de los responsables de los proyectos (Able to Include).

En la tercera fase, de definición de requisitos y del contexto de uso, se registra una alta participación de los usuarios en las actividades destinadas a establecer sus características y los requisitos, mientras que es inferior en las actividades de definición de la funcionalidad del diseño, del reparto de tareas persona-ordenador y de la definición del entorno técnico. La participación más baja la recibe la definición 
del entorno cultural y social de los usuarios al realizar las tareas. Cabe recordar que, en el caso concreto del contexto técnico, físico, social y cultural, la norma ISO 924I:2 I0:20IO los recoge como requisitos y los considera básicos para el diseño y la evaluación?.

Los resultados recopilados no arrojan datos sobre la descripción de tareas que puedan influir en la usabilidad y la accesibilidad.

En suma, el análisis de otros aspectos del contexto de uso como la funcionalidad, el reparto de tareas, el entorno técnico, el físico ${ }^{\mathrm{Io}}$, y especialmente el cultural y social no parecen estar aún tan arraigados en este tipo de proyectos como el análisis del usuario y sus necesidades.

En la cuarta fase, de desarrollo del producto, las actividades de los usuarios se centran más en la evaluación de los textos y de las herramientas (DCU 6 del ciclo de vida) que en el proceso de desarrollar propuestas de diseño en sí (DCU 5), más orientado a desarrollar modelos de tareas, opciones de diseños, prototipos o la capacitación o formación del usuario.

En la última fase, de lanzamiento y mantenimiento, se observa una participación elevada respecto a las actividades de marketing, pero reducida respecto a las actividades de mantenimiento.

\subsection{Convergencia de los resultados teóricos y empíricos}

A continuación se relacionan los resultados de la revisión documental y del benchmarking empírico. A pesar de ser dos metodologías con objetivos distintos, una centrada en la accesibilidad cognitiva de los textos y otra

9. La tabla original en inglés puede descargarse de: http://webdiis.unizar.es/asignaturas/IPO/wp-content/uploads/2OI3/O2/ Checklist-ISO-924I-2IO.pdf (acceso 8 de junio de 20I6). Io. Este aspecto, aun siendo relevante no se incluyó en el cuestionario. Llama la atención que ninguno de los entrevistados hizo referencia a él en los campos y preguntas abiertas. en proporcionar usabilidad y experiencia de usuario adecuadas en la interacción personaordenador, coinciden en su afán por satisfacer las necesidades de los usuarios. El estudio de la LF desde la perspectiva del DCU no persigue calificar su modo de actuación, sino acercarla a una metodología afianzada e instaurada en el ámbito tecnológico, que puede servir de guía en proyectos digitales de LF.

En general, se identifica una afinidad de la metodología de la lectura fácil con los principios y la práctica de la metodología del DCU. Tanto en la revisión documental como en el benchmarking se detecta una preocupación básica desde la LF por involucrar y situar al usuario en el centro de las actividades de diseño. El concepto de usuario de la LF coincide en su totalidad con el del DCU, es decir, va más allá del usuario final del que exigen su identificación y caracterización adecuadas - e integran a las partes interesadas ya sean familiares, cuidadores, profesores $\mathrm{u}$ organizaciones, a las que involucran en el desarrollo de los diseños. Un aspecto coincidente en las dos vertientes respecto a los usuarios meta es su heterogeneidad básica, la necesidad de definirlos con más precisión y, como se avisa en la vertiente teórica, la imposibilidad de ofrecer soluciones universales.

Respecto al principio I del DCU, sobre el conocimiento expreso del contexto de uso (usuarios, tareas y entorno), la LF y el DCU presentan una afinidad completa respecto al usuario, pero inferior respecto a las tareas y el entorno técnico, físico, social y cultural. En ambas vertientes se demuestra que la necesidad de conocer las necesidades de los usuarios está muy arraigada en los proyectos de LF.

Si bien en la vertiente A, teórico-prescriptiva, se hace referencia a las habilidades de los usuarios, a las barreras y, en dos casos, a la necesidad de diseñar de forma accesible, en la parte empírica se identifica que esta preocupación abarca principalmente la usabilidad y la accesibilidad en los proyectos de los ámbitos más tecnológicos.

Por último, el entorno social y cultural parece ser, desde el punto de vista del DCU, el aspecto 
del contexto de uso que menos se observa tanto en la teoría como en la práctica.

Respecto al principio 2, sobre la participación activa del usuario durante todo el proceso de diseño y desarrollo, la necesidad de integrar a los usuarios y de planificar dichas actuaciones se identifica en los proyectos y es acorde con los datos teóricos, especialmente en la recogida de requisitos y en los procesos de validación y de evaluación de la calidad. Más aún, en los proyectos se identifica una participación muy elevada de los usuarios en la fase de concepción, tal y como se insta en uno de los documentos de la parte teórica con el fin de aumentar el interés y crear actitudes positivas por los productos en LF.

Los proyectos arrojan además datos más concretos respecto a las áreas que necesitan un mayor desarrollo, como son las fases de implementación, difusión, seguimiento y mantenimiento. Como indica el interlocutor de uno de los proyectos, la intervención de los usuarios en las fases de marketing y de lanzamiento de nuevos productos influye positivamente en la imagen y el concepto existentes, puesto que les permite actuar en contextos de los que hasta ahora habían estado excluidos o representados por otros actores. Respecto a la fase de mantenimiento y soporte, las conclusiones de uno de los interlocutores sobre la necesidad de aumentar la participación en esta fase coinciden con los resultados obtenidos en los proyectos, donde la participación es menor en las actividades de creación de soluciones de diseño (DCU5) en la que se comienza a preparar la capacitación y el soporte del usuario.

Respecto al principio 3, sobre la evaluación y el refinamiento, los resultados de las dos vertientes coinciden en la importancia de la participación del usuario en esta actividad. En los proyectos no se obtienen referencias sobre si las validaciones técnicas de la herramienta han incluido las pautas de WCAG 2.0 del W 3 C. En cuanto a la revisión de la comprensibilidad de los textos, en todos los casos se incluye a los usuarios, especificándose en dos casos que se trata de un tipo de validación triple.
Respecto al principio 4, iteración, los datos de las vertientes de análisis coinciden, no siendo lo suficientemente claros respecto a la existencia de iteraciones en otras fases distintas a las de la evaluación. Por tanto, se presume un carácter lineal con iteraciones en la fase de evaluación. En el análisis documental se encuentra una referencia a favor de más iteraciones que, según el DCU, son necesarias, ya que el usuario no es capaz de expresar todas sus necesidades y requisitos de una sola vez. Frente a esta necesidad, que en la vertiente A justifica además la prolongación de los tiempos de realización, se encuentran los testimonios de los interlocutores de los proyectos que señalan la falta de tiempo como un problema frecuente y limitante de la participación.

Respecto al principio 5, sobre la experiencia de usuario, se encuentran referencias aproximativas en la vertiente teórica sin llegar a estar tan arraigada como en el DCU. Este desarrollo coincide con los resultados empíricos, donde este aspecto recibe una mayor atención en los proyectos tecnológicos, con referencias concretas a la participación de los usuarios en la validación de las herramientas, de los diseños y de las funcionalidades. De su intervención se infiere que en el proceso transmiten y articulan sus expectativas, preferencias y experiencia, y que esta es parte de los objetivos del diseño. En el proyecto de la Universidad de Valencia, la interlocutora especifica que "[...] la experiencia subjetiva de los participantes en diferentes versiones de la tarea de lectura es esencial para sacar conclusiones".

Respecto al principio 6, sobre la naturaleza multidisciplinar de los equipos, esta fue reducida en la vertiente teórica mientras que en los proyectos se detecta un mayor carácter multidisciplinar que cuenta con la participación de los usuarios en el equipo del proyecto y en diversas fases del ciclo de vida, así como en actividades de distinta naturaleza, aunque sigue predominando en la validación.

En uno de los proyectos, la interlocutora resalta el "trabajo colectivo" (Diccionario Online) como uno de los beneficios del proyecto. Sin embargo, también se identifican las áreas 
menos desarrolladas, como en el proyecto Able to Include, donde el interlocutor resalta la necesidad de definir métodos para favorecer la participación en la fase de mantenimiento y explotación. En este mismo caso, se menciona la falta de metodologías de guía.

Por último, respecto a la sostenibilidad, la tendencia observada en la revisión documental de establecer principios en torno a la LF, trabajar según pautas, orientar la producción a la demanda de los usuarios y establecer criterios de calidad se refleja en todos los proyectos. Aunque la forma de actuar es similar en la muestra analizada a nivel teórico, en la práctica no parece existir consenso en la forma de proceder o en criterios mínimos de calidad más allá de la redacción o la comprensión, lo cual se refleja en la demanda de metodologías estándar proveniente de los mismos actores, y en la mayor participación en este tipo de actividades.

Para concluir, la afinidad detectada es mayor en los ámbitos más tecnológicos. En esta área, aunque los documentos analizados señalan la necesidad de crear interfaces amistosas y diseños usables y accesibles digitalmente según las WCAG 2.0 $\mathrm{W}_{3} \mathrm{C}$, se identifica un vacío tanto a nivel de pautas como de actuación y de existencia de datos empíricos.

Conforme aumente la oferta de productos digitales en LF, mayor será la necesidad de otorgar también suficiente atención a la interacción y de recurrir desde un principio a metodologías que garanticen la usabilidad, que creen experiencias de usuario satisfactorias y que salvaguarden la cadena de accesibilidad, así como de compartir experiencias y metodologías entre los actores. Respecto al enfoque DCU, se identifica como una metodología compatible.

\section{Discusión de los resultados}

Aunque los datos obtenidos en las vertientes de estudio son suficientes para reconocer una afinidad entre estas dos metodologías, tanto en la teoría como en la práctica, carecen de valor estadístico y no pueden utilizarse para realizar juicios absolutos. A tal propósito, sería necesario recoger datos más exactos sobre cada fase del ciclo de vida en un mayor número de proyectos. No obstante, se concluye que la hipótesis de partida se corrobora en las dos vertientes de trabajo y, al tiempo, permite establecer áreas de menor afinidad. No se identifican incompatibilidades o factores antagonistas.

En el trabajo teórico y en el práctico se identifica una gran proximidad de la LF a los principios del DCU respecto al entendimiento de quién es el usuario y su función de agente experto y fuente de información en las fases de recogida de requisitos y de evaluación de la calidad del producto final, ya sea texto o herramienta. En estos casos, las referencias obtenidas son directas y se consideran suficientes.

Desde el punto de vista del contexto de uso del DCU en sus tres componentes: usuario, tareas y entorno, se identifica la necesidad de profundizar en lo referente a los dos últimos. Una mayor atención a estos aspectos y a su adaptación es conforme con el modelo actual del funcionamiento humano y permitiría agrupar a los usuarios poniendo un mayor énfasis en los conocimientos y experiencias previas, las áreas de interés y los objetivos. Este tipo de datos, más allá de la discapacidad funcional, contribuirían también a desarrollar otras áreas como la multimodalidad y la adaptatividad de las interfaces y, por ende, la personalización de los productos.

Dada la naturaleza de la metodología de la LF y aunque se menciona el formato digital en las publicaciones, las fuentes teóricas no profundizan en las implicaciones para el usuario de interaccionar en un medio tan distinto, donde aspectos tan relevantes como la usabilidad, la experiencia de usuario y la accesibilidad al medio requieren la misma atención que la comprensibilidad de los textos. Ampliar y enriquecer la metodología de la LF con aspectos como la experiencia del usuario en el mundo digital permitirá crear en este 
ámbito soluciones individualizadas coherentes con el modelo actual, llegando incluso a generar nuevas demandas. En cualquiera de los casos, contribuirían a desestigmatizar la discapacidad intelectual, fomentar la autodeterminación y reducir el potencial de "exclusión" que ciertos autores otorgan a la LF.

El cumplimiento de los estándares WCAG 2.0 no ha podido valorarse y debe ser objeto de estudios posteriores de forma que soporten y amplíen el trabajo del consorcio $\mathrm{W}_{3} \mathrm{C}$.

El menor número de coincidencias respecto a equipos de trabajo multidisciplinares en la literatura difiere de los datos en la vertiente $\mathrm{B}$, donde queda claro que forman parte del equipo de los proyectos. No obstante, cabe mencionar que se trata de proyectos con una trayectoria bastante afianzada que cuentan con la colaboración de expertos y otros medios económicos. Por tanto, queda por indagar cómo se trabaja a menor escala, de qué recursos disponen los actores y a qué tipo de material o métodos tienen acceso.

Respecto al principio de iteración, en la LF está más limitado a la validación de los textos, aunque en los proyectos del ámbito tecnológico de la vertiente empírica sí se incluye respecto al diseño de las herramientas. De todas formas, el cuestionario no permite profundizar en el número y el momento de las iteraciones realizadas, si bien parece que se consideran necesarias y, en el caso de la validación de textos, incluso existe un proceso reconocido de triple validación.

Asimismo, sería necesario indagar en el tipo de pruebas y de validaciones realizadas respecto a la herramienta informática y averiguar si abarcan la usabilidad y la experiencia de usuario, o bien solo la usabilidad.

La asignación de recursos y de funciones, y la remuneración dentro de los equipos del proyecto son aspectos que no han podido analizarse en este trabajo.

Otro aspecto extraído en las vertientes es el hecho de que el modo de pensar actual en torno a la forma de proceder en proyectos de LF no es específica de un país, sino similar en los países de origen estudiados. Por tanto, puede inferirse que la LF sigue un desarrollo paralelo, por lo menos, en los países con un nivel socioeconómico parecido. Este hecho podría potenciarse mediante la creación de plataformas y grupos de trabajo internacionales.

Finalmente, se concluye que las vertientes de trabajo han permitido corroborar la afinidad presupuesta entre ambas metodologías y la posibilidad de un acercamiento futuro mayor que permita asegurar la calidad, contribuir a la difusión de estos productos y a generar datos empíricos. El acercamiento sería también coherente con el modelo actual de discapacidad, que subraya la importancia del contexto y de su capacidad para ser modificado a fin de reducir los requisitos que impone al usuario.

\section{Conclusiones finales y propuestas para trabajos futuros}

La hipótesis de partida de que ambas convergen ya en numerosos aspectos ha podido verificarse en el estudio. Asimismo, se ha constatado que no existe aún una metodología estándar a la hora de crear productos digitales de LF, al no haberse encontrado referencias directas en ninguno de los documentos ni en los datos provenientes del cuestionario.

En ambas vertientes, teórica y empírica, se ha constado que la forma de actuación vigente exige un conocimiento riguroso del usuario y del contexto en el desarrollo de productos de LF. Este enfoque coincide con el modelo actual en vigor del funcionamiento humano. Según la definición de apoyos vista en el estado de la cuestión, los resultados obtenidos apoyan la definición del LF y del DCU como estrategias transversales de apoyo.

A través de la metodología de revisión documental, se identificó una base sólida a nivel 
de texto, pero no lo suficientemente exhaustiva al poner en práctica proyectos de LF digitales. Si bien las pautas redaccionales son detalladas, las referencias al medio digital tan solo proporcionan información básica, de carácter introductorio, donde se alerta sobre la necesidad de asegurar la accesibilidad, la usabilidad y de crear interfaces amistosas. En el trabajo empírico, los proyectos de Able to Include y Klar Tale expresan esta falta de metodología en general y la necesidad de que ambos procesos, el de creación del texto en LF y el del diseño discurran de forma paralela. En general, se identifica una falta de datos empíricos respecto a la recepción de los textos, a la usabilidad y a la experiencia de usuario.

Respecto al proceso de redacción, los datos empíricos subrayan el uso de pautas, siendo las de Inclusion Europe las más referenciadas. En los proyectos, el uso de pautas recibe valoraciones diferentes desde ser una guía hasta no ser necesarias al disponerse de la experiencia suficiente. En todos los casos, el criterio adicional de la calidad de los textos es la evaluación por parte de los usuarios. Las implicaciones y el tipo de dependencia entre estos dos factores a la hora de difundir y aumentar la producción de textos en LF en un futuro no es clara aún.

La información sobre el ciclo de vida de proyectos de LF desde el punto de vista del DCU descubre que el usuario participa especialmente en la fase de concepción y de alineamiento de las necesidades de los usuarios con el mercado y los objetivos organizacionales. En esta fase se recurre a una metodología apoyada en dos perspectivas complementarias, por un lado, fuentes primarias (entrevistas, consultas, monitorización continua, retroalimentación directa, etc.) y, por el otro, fuentes secundarias (literatura científica, colaboración interuniversitaria, datos estadísticos, etc.).

Los proyectos incluyen en su planificación la participación de los usuarios en distintas fases y actividades. En la validación de los textos, en los proyectos del Diccionario Online Lectura Fácil y de la Agencia Leicht gesagt, especifican un procedimiento de validación triple. Según los datos del proyecto Able to Include, en la validación de las herramientas se utilizaron cuestionarios y grupos focales en la definición de la herramienta, así como grupos de trabajo en la validación del diseño, la herramienta y sus funcionalidades. En el proyecto Léelo Fácil, oneclick realizó pruebas con usuario en aula y pruebas de la interfaz, de las imágenes y de los textos. En los test de usuario, la editorial utilizó la herramienta redmine.

Respecto a la necesidad del desarrollo de metodologías que permitan la participación, el proyecto Able to Include apunta no solo su necesidad en la validación, sino también en las fases de mantenimiento y explotación. Más aún, el interlocutor especifica la necesidad de que tal metodología esté disponible para servir de guía a cualquier proyecto. En el proyecto Klar Tale se apunta la necesidad de metodologías para testar también a distancia y la dificultad de realizar pruebas con usuarios cuando se trata del backend o parte de servidor.

En cuanto a la definición del contexto de uso según la perspectiva del DCU, los proyectos incluyen la participación de los usuarios no solo en el análisis de los requerimientos, sino también en la definición de las tareas y del entorno. Aunque se trate de una muestra reducida y los proyectos y actores cuenten con una trayectoria consolidada en este ámbito, se concluye una coherencia con el modelo de funcionamiento humano. De todos los aspectos del entorno estudiados, el cultural y el social recibieron menor atención.

El análisis de qué, cómo y por qué se realizan las tareas, así como del entorno en el que tienen lugar es una forma de acercamiento al usuario que lo desliga en parte de sus características funcionales. Esta actuación es válida para grupos meta heterogéneos y ofrece una vía de solución a los problemas ya mencionados en torno a la heterogeneidad y a la restricción a la discapacidad intelectual.

Por último, en la fase de lanzamiento y mantenimiento del producto, los usuarios 
intervienen en los proyectos en diversas actividades de marketing tanto a través de distintos medios y publicaciones científicas como participando en presentaciones y exposiciones. En la vertiente documental, la publicación Five principles for producing better information for disabled people propone un proceso centralizado de provisión de la información mediante la creación de puntos de acceso a toda la información en LF y la referenciación consciente entre todos aquellos proveedores de información, ya sean programas nacionales, locales, iniciativas privadas, públicas o trabajo de voluntariado. Queda por esclarecer hasta qué punto este modo de actuación está implementado a nivel nacional e internacional tanto respecto a la provisión de información como a la colaboración y disponibilidad de materiales de creación. Respecto a las tareas de mantenimiento, sin embargo, la participación es menor y, como se apuntaba ya anteriormente, se identifica la necesidad de desarrollar y difundir métodos.

Finalmente, como metodología efectiva a la hora de realizar el proyecto Léelo Fácil, la editorial oneclick apuntó el empleo de la metodología SCRUM, de proyectos ágiles.

Resumiendo, la convergencia de las dos líneas de estudio ha permitido establecer una afinidad entre el pensamiento y las prácticas actuales en el ámbito de la lectura fácil con las actividades y los principios del diseño centrado en el usuario, así como evidenciar que ya se implanta en gran medida en proyectos actuales.

En cuanto a las propuestas para estudios futuros, la heterogeneidad de los grupos meta identificada en la revisión documental y en la parte empírica parte de una aceptación básica y de expectativas comunes entre los grupos ya que, de facto, solo incluyen a las personas con discapacidad intelectual. Se determina, pues, la necesidad de estudiar más a fondo los grupos y la heterogeneidad dentro de cada uno de ellos, lo cual coincide con la necesidad establecida de definir por igual el contexto de uso en sus tres elementos. En esta misma línea, y teniendo en cuenta que los turistas, los emigrantes y los estudiantes de idiomas forman parte del público meta, podría evaluarse su eficacia en el aprendizaje de idiomas. Una introducción de la LF en este ámbito podría contribuir a impulsarla, difundirla y a prevenir una percepción equivocada respecto al tipo de beneficiarios.

En relación a los ámbitos, dada la falta de oferta de versiones en LF identificada en el área de medios audiovisuales, podría evaluarse cuál es el estado de la legislación, qué tipo de apoyo resulta más idóneo para este público, comparando técnicas como el subtitulado y la audiodescripción, e indagar la posibilidad de crear versiones, orales o escritas, en LF. En el campo de la documentación técnica, podría comprobarse qué demanda real existe, si puede suplirse con lenguaje sencillo, si es necesario elaborar versiones en LF y qué publicaciones del ámbito técnico y administrativo-jurídico exigen llevar un sello de LF. Este podría ser el caso de productos que puedan suponer un peligro para la seguridad de las personas o donde un manejo/entendimiento indebido pudiera derivar en acciones legales o la exigencia de compensaciones económicas de algún tipo.

La ampliación de los ámbitos de actuación de la LF implica, asimismo, la formación de los autores. Por tanto, sería necesario definir una estrategia de formación, ya sea formación continuada o mediante la adaptación de planes de estudio de las correspondientes carreras de grado o máster - sobre todo en el ámbito de la comunicación y del software-. En todos estos contextos de formación y educación, la LF requiere formatos digitales accesibles.

Por último, sería importante estudiar el impacto social, económico o ambiental posteriores de los proyectos en curso, su accesibilidad según WCAG 2.0 y satisfacer la necesidad identificada de disponer de metodologías de guía a la hora de realizar proyectos. 
Referencias bibliográficas

Accessible Information Working Group, AIWG (20I I): Make it easy: A guide to preparing Easy to Read Information (en línea). http://www. walk.ie/userfiles/file/Make \% 2oIt \% 2oEasy \% 20 - $\% 20 \mathrm{~A} \%$ 2oguide $\%$ 20to $\%$ 2opreparing $\% 20$ Easy \% 20to \% 20Read\% 2oInformation.pdf, acceso I 5 de abril de 2016 .

Batthyány, K. et al. (20I I): Metodología de la investigación en Ciencias Sociales: Apuntes para un curso inicial. Montevideo: Departamento de Publicaciones, Unidad de Comunicación de la Universidad de la República (UCUR).

Bock, B. y Lange, D. (201 5): "Was ist eigentlich Leichte Sprache?”, en Candussi, K. y Fröhlich, W. (coords.): Leicht Lesen: der Schlüssel zur Welt. Wien: Editorial Böhlau.

Boxwell, J. R. Jr. (2006): Benchmarking para competir con ventaja. Madrid: McGraw-Hill/ Interamericana de España.

Bredel, U. y Maaß, C. (2016): Leichte Sprache: Theoretische Grundlagen - Orientierung für die Praxis. Berlin: Duden.

Carreras, O. (2015): Usableaccesible. WCAG 2.0 Extensions. „WCAG Cognitive Extension“, „WCAG Mobile Extension“, y nueva versión de las WCAG 2.0 (en línea). <http:// olgacarreras.blogspot.com.es/20I 5/I I/wcag-2Oextensions-wcag-cognitive.html>, acceso $30 \mathrm{de}$ agosto de 2016.

Change (20I 5): How to make information accessible (en línea). <http://www. changepeople.org/getmedia/923a6399-cI $3 \mathrm{f}$ -


accessible-guide-20I6-Final>, acceso I7 de abril de 2016.

Estruga, A. (2015): Letras Para Todos 20/I I/20I 5 - II Encuentro Nacional de Buenas Prácticas en Lectura Fácil (en línea). <https://www.youtube.com/ watch? $v=V b 4$ v_fmqVe 4 \&index $=\mathrm{I} \&$ list=PLOY SZ9PWmQ7 \&nohtml $5=$ False>, acceso 7 de abril de $20{ }_{5}$.
Fajardo, I. et al. (2013): "Easy-to-read Texts for Students with Intellectual Disability: Linguistic Factors Affecting Comprehension". Journal of Applied research in Intellectual Disabilities, 27 (3): 2I $2-225$.

Feaps Madrid (2014): Accesibilidad Cognitiva: Guía de Recomendaciones (en línea). <http:// plenainclusionmadrid.org/recursos/guiarecomendaciones-accesibilidad-cognitiva/>, acceso 20 de mayo de 2016.

Fröhlich, W. y Candussi, K. (2OI 5 ): "Informationsbarrieren und Wege zu ihrer Überwindung “, en Candussi, K. y Fröhlich, W. (coords.): Leicht Lesen: der Schlüssel zur Welt. Wien: Editorial Böhlau.

García, O. (20 I 2): Lectura fácil: métodos de redacción y evaluación (en línea). <http://www. plenainclusion.org/sites/default/files/lecturafacil-metodos.pdf $>$, acceso 3 de abril de 20 I 6 .

International Federation of Library Associations and Institutions, IFLA (2010): Directrices para materiales de lectura fácil (en línea). <https:// dilofacil.wordpress.com/20 г 2/OI/24/ las-pautas-de-lectura-facil-de-la-ifla-enespanol/>, acceso 22 de abril de 2016 .

Imserso (20I 5 ): Base estatal de datos de personas con valoración del grado de discapacidad (informe a 3I/I2/20I5) (en línea). <http:// imserso.es/InterPresent2/groups/imserso/ documents/binario/bdepcd_20I5.pdf >, acceso 27 de mayo de 2017.

Inclusion Europe (2009): Información para todos. Reglas europeas para hacer información fácil de leer y comprender (en línea). <http:// www.plenainclusion.org/sites/default/files/ informacion_todos.pdf $>$, acceso 22 de abril de 2016.

International Organization for Standardization, ISO (2010): Ergonomics of human-system interaction - Part 2 I0: Human-centred design for interactive systems. ISO 924I-210. 2010. Ginebra: ISO. 
International Organization for Standardization, ISO (200I): Directrices para la documentación de sistemas de gestión de la calidad (en línea). <https://www.iso.org/obp/ ui/\#iso:std:iso:900I:ed-4:v2:es>, acceso 28 de julio de 2016.

International Organization for Standardization, ISO (2000): Ergonomics - Ergonomics of human-system interaction - Human-centered lifecycle process descriptions. ISO/TR I 8529. 2000. Ginebra: ISO.

Maram, L. (2013): Qué es y cómo hacer benchmarking; 5 ejemplos de sustentabilidad (en línea). <http://www.luismaram. com/2OI $3 / 08 / 28 /$ como-hacer-benchmarking-ensustentabilidad/>, acceso I 4 de julio de 2016 .

Netzwerk Leichte Sprache (2014): Regeln für das Qualitäts-Siegel (en línea). <http://www. leichtesprache.org/images/Regeln_fr_das_ Qualitts Siegel.pdf>, acceso 2 de mayo de 2016.

Norman, D. (2013): The design of everyday things. Nueva York: Basic Book.

Ocampo, A. (201 5). Lectura para todos. El aporte de la fácil lectura como vía para la equiparación de oportunidades (en línea). <http://www. upla.cl/inclusion/wp-content/uploads/20 I 5/05/ LECTURA-PARA-TODOS.pdf $>$, acceso I 3 de junio de 2016.

Observatorio Estatal de la Discapacidad, OED (20I 5): La accesibilidad cognitiva en España. Estado de situación (en línea). <http:// observatoriodeladiscapacidad.info/documentos/ documentos-oed/I6-accesibilidad/68-laaccesibilidad-cognitiva-en-espana-estado-desituacion.html>, acceso 20 de junio de 2016.

Olimpiadas Especiales (2016): ¿Qué es la discapacidad intelectual? (en línea). <http:// www.specialolympics.org/>, acceso I 2 de agosto de 2016.

Reino Unido, Departamento de Salud (2010): Making written information easier to understand for people with learning disabilities. Guidance for people who commission or produce Easy Read information - Revised Edition 20 Io (en línea). <https://www.gov. uk/government/publications/making-writteninformation-easier-to-understand-for-peoplewith-learning-disabilities-guidance-for-peoplewho-commission-or-produce-easy-read-information-revised-edition-20Io>, acceso I 5 de abril de 2016.

Reino Unido, Oficina de Asuntos sobre Discapacidad (2007). Five principles for producing better information for disabled people (en línea). <http://webarchive. nationalarchives.gov.uk/+/http:/www. officefordisability.gov.uk/docs/ODI_ FivePrinciples_2007.pdf $>$, acceso 20 de abril de 2016.

Schädler, J. y Reichstein, M. (2OI 5 ): "Leichte Sprache und Inklusion “, en Candussi, K. y Fröhlich, W. (coords.): Leicht Lesen: der Schlüssel zur Welt. Wien: Editorial Böhlau.

Scior, K. et al. (201 5): Discapacidades intelectuales: Sensibilización y lucha contra la estigmatización evaluación mundial. Resumen ejecutivo y recomendaciones. Londres: University College London (en línea). <https://www.ucl.ac.uk/ ciddr/publications $>$, acceso 22 de junio de 2016.

Verdugo, M. A. y Schalock, R. L. (2010): "Últimos avances en el enfoque y concepción de las personas con discapacidad intelectual". Siglo cero, 4I (4): 7-2I (en línea). <http://www. plenainclusion.org/sites/default/files/sc_236. pdf $>$, acceso 22 de mayo de 2016.

Vived, E. y Molina, S. (20I2): Lectura fácil y comprensión lectora en personas con discapacidad intelectual. Zaragoza: Prensas de la Universidad de Zaragoza.

Wehmeyer, M. L. et al. (2008): El constructo de discapacidad intelectual y su relación con el funcionamiento humano. Siglo cero, 39 (3): 5-I 8 (en línea). <http://www.plenainclusion. org/sites/default/files/sc_227.pdf>, acceso 4 de julio de 2016. 


\section{Anexo I. Cuestionario}

Estimado participante:

Le agradezco que comparta con nosotros su experiencia en proyectos de lectura fácil.

Como sabe, estamos investigando en qué medida los proyectos de lectura fácil incluyen al usuario en su desarrollo, es decir, hasta qué punto se aplican los principios del diseño centrado en el usuario, abreviado DCU, propio de los productos interactivos.

Nuestro objetivo es crear una relación de buenas prácticas y desvelar el tipo de metodología que se está aplicando en este campo.

A tal propósito, estamos comparando proyectos internacionales. De ahí que su participación sea de gran ayuda, y le agradecemos enormemente que le dedique tiempo al cuestionario.

La información recogida servirá para:

- Fomentar el intercambio de información sobre la lectura fácil.

- Analizar cuál ha sido hasta ahora el papel del usuario en los proyectos de la lectura fácil. Compartir buenas prácticas entre las personas que trabajan en este ámbito.

- Detectar pasos que no se realizan y que sería positivo incorporar. Establecer una comparación entre el proceso de redacción en la lectura fácil y el proceso llamado diseño centrado en el usuario.

El diseño DCU es un proceso que se utiliza en el diseño de productos interactivos (páginas de Internet, libros digitales, apps, etc.). El objetivo del DCU es diseñar de forma que los productos se ajusten lo más posible a las necesidades y deseos de los usuarios. De esta forma, los usuarios los usan más y están más satisfechos.

Respecto al cuestionario, usamos el término "usuarios” para hacer referencia a las personas que usan los textos o los servicios de lectura fácil. El término "parte interesada" o "stakeholder", para aquellas personas que se ven afectadas por el proyecto, ya sea un cliente, un organismo, una empresa, programadores, personal técnico o de mantenimiento, etcétera.

El objetivo del cuestionario es recoger información. Es decir, todas las respuestas son válidas y correctas. Por tanto, aporte toda la información que desee. No hay límite.

Una vez más, muchas gracias por su participación. Si tuviera alguna pregunta, no dude en ponerse en contacto conmigo a través de los datos que aparecen arriba.

Atentamente,

Rocío Bernabé Caro. 


\section{Datos sobre el participante}

I. ¿Cuál es su función actual?

2. ¿Qué relación tiene su función actual con la lectura fácil?

3. ¿Qué experiencia tiene en el área de la lectura fácil?

\section{Datos sobre el proyecto}

En este apartado nos interesa conocer su experiencia en el proyecto.

El término proyecto se usa en el cuestionario para hacer referencia al producto o servicio en lectura fácil. Para contestar la primera pregunta, escoja la palabra que mejor lo define: página web, diccionario, boletín de noticias, programa de simplificación, etcétera.

El término parte interesada o stakeholder hace referencia a las personas que afectan o se ven afectadas por el proyecto, ya sean externas o internas y de jerarquías diferentes, por ejemplo: un organismo, una empresa, programadores, personal técnico o de soporte, socios, comité directivo, etcétera.

I. Nombre del proyecto:

2. ¿En qué fase se encuentra el proyecto actualmente? Escriba una X detrás de la respuesta adecuada y añada la información que le parezca oportuna.

- Planificación:
- Desarrollo:

- Implementación y mantenimiento:

- Finalizado:

- Otra: (por favor, especificar):

3. ¿Cuál fue o es su papel en el proyecto?

4. ¿Cuál fue el factor desencadenante del proyecto?

5. ¿Qué demanda cubría el proyecto?

6. ¿Qué métodos se usaron para determinar los beneficios del proyecto? (Estudios de mercado, previsiones, entrevistas, etc.).

7. ¿Qué pautas de redacción o adaptación se utilizaron o utilizan? (IFLA, Inclusion Europe, otras).

8. ¿Desea añadir información adicional?

\section{Datos sobre el papel del usuario y los} stakeholders

Las preguntas de este apartado se refieren a la participación de los usuarios y partes interesadas o stakeholders. 
Las preguntas se han redactado en pasado. Si este tiempo verbal no fuera válido en su caso y desea especificarlo, hágalo según considere oportuno.

Enumere los grupos de usuarios y las partes interesadas o stakeholders identificados.

I. ¿Cuáles de estos usuarios o stakeholders enumerados participaron en el proyecto?
2. ¿Qué criterios aplicó para seleccionar a los usuarios y partes interesadas o stakeholders que participaron en el proyecto?
3. ¿Cómo contactó con los usuarios y partes interesadas o stakeholders que participaron en el proyecto?

4. ¿En qué fases del proyecto participaron los usuarios y stakeholders? Marque con una X según corresponda y añada la información que estime oportuna.

5. ¿Qué métodos de participación utilizó a la hora de involucrar a los usuarios y a los stakeholders? Por favor, describa el método y la fase en la que se utilizaron.

\begin{tabular}{|c|c|c|c|}
\hline Fase del proyecto & Actividad & Usuarios & Stakeholders \\
\hline \multirow{2}{*}{ Concepción } & Desarrollar la idea del proyecto & & \\
\hline & Analizar la demanda de la idea del proyecto & & \\
\hline \multirow{2}{*}{ Planificación } & $\begin{array}{l}\text { Usuarios/stakeholders formaron parte del equipo del } \\
\text { proyecto }\end{array}$ & & \\
\hline & $\begin{array}{l}\text { La participación de los usuarios/stakeholders estuvo } \\
\text { incluida en la planificación }\end{array}$ & & \\
\hline \multirow{5}{*}{$\begin{array}{l}\text { Definición } \\
\text { de los } \\
\text { requerimientos y } \\
\text { del contexto de uso }\end{array}$} & Especificar las necesidades de los usuarios y stakeholders & & \\
\hline & Especificar los requerimientos de funcionalidad & & \\
\hline & Definir las tareas que realizarán los usuarios & & \\
\hline & $\begin{array}{l}\text { Definir el entorno técnico de los usuarios al realizar las } \\
\text { tareas (hardware, programas, etc.) }\end{array}$ & & \\
\hline & $\begin{array}{l}\text { Definir el entorno cultural y social de los usuarios al realizar } \\
\text { las tareas }\end{array}$ & & \\
\hline \multirow{2}{*}{$\begin{array}{l}\text { Desarrollo } \\
\text { del producto }\end{array}$} & $\begin{array}{l}\text { Participación del usuario/stakeholders en la creación de } \\
\text { soluciones de diseño }\end{array}$ & & \\
\hline & $\begin{array}{l}\text { Participación del usuario/stakeholders en la evaluación de } \\
\text { prototipos }\end{array}$ & & \\
\hline Lanzamiento & $\begin{array}{l}\text { Participación del usuario/stakeholders en las actividades de } \\
\text { marketing }\end{array}$ & & \\
\hline Mantenimiento & $\begin{array}{l}\text { Participación del usuario/stakeholders en el soporte y la } \\
\text { formación de los usuarios }\end{array}$ & & \\
\hline $\begin{array}{l}\text { Otras } \\
\text { (por favor, } \\
\text { especificar). }\end{array}$ & & & \\
\hline
\end{tabular}




\section{Recapitulación}

I. En su opinión, ¿cómo influyó la retroalimentación y la participación de los usuarios y los stakeholders en el proyecto?

2. En su opinión, ¿`cuáles fueron las medidas, pasos o métodos más efectivos en el proyecto?
3. En su opinión, ¿qué faltó respecto a la participación de los usuarios y partes interesadas o stakeholders?

4. ¿Desea añadir información adicional?

Muchas gracias por su participación 
Anexo II. Tabla de los proyectos participantes

A continuación, se presentan los proyectos de forma breve y ordenados por ámbito de actuación e idioma.

\begin{tabular}{|c|c|c|c|}
\hline Ámbito ${ }^{11}$ & Idioma $^{12}$ & Nombre del proyecto & País y descripción \\
\hline \multirow[t]{3}{*}{$\begin{array}{l}\text { Actualidad } \\
\text { y noticias }\end{array}$} & $\begin{array}{l}\text { EN, ES } \\
\text { DE, FR, }\end{array}$ & $\begin{array}{l}\text { Easy-to-read Newsletter: } \\
\text { Europe for us! }\end{array}$ & $\begin{array}{l}\text { Bélgica. Boletín electrónico informativo de la } \\
\text { Plataforma Europea de Autogestores. Editado } \\
\text { en inglés, se traduce al español, al alemán y al } \\
\text { francés. }\end{array}$ \\
\hline & NO & $\begin{array}{l}\text { Rediseño y lanzamiento del } \\
\text { nuevo portal de noticias } \\
\text { Klar Tale }\end{array}$ & $\begin{array}{l}\text { Noruega. Portal de noticias del periódico } \\
\text { semanal Klar Tale. Existe desde 2005, en abril de } \\
2016 \text { se relanzó con un nuevo diseño responsive } \\
\text { y una nueva plataforma. } \\
\text { www.klartale.no/ }\end{array}$ \\
\hline & SE & 8 Sidor & $\begin{array}{l}\text { Suecia. Portal de noticias del periódico semanal } \\
8 \text { Sidor. Puede abonarse en papel, en PDF y en } \\
\text { audio. } \\
\text { 8sidor.se/ }\end{array}$ \\
\hline \multirow[t]{2}{*}{$\begin{array}{l}\text { Administración y } \\
\text { asociaciones }\end{array}$} & $D E$ & $\begin{array}{l}\text { Leichte Sprache in der } \\
\text { Landesverwaltung } \\
\text { (Lectura Fácil en la } \\
\text { Administración del } \\
\text { Estado Federado de } \\
\text { Baden-Wurttemberg) }\end{array}$ & $\begin{array}{l}\text { Alemania. Proyecto de la Federación regional de } \\
\text { Lebenshilfe }{ }^{13} \text { de Baden-Wurttemberg. } \\
\text { El proyecto tiene una duración total de un año. } \\
\text { www.lebenshilfe.de }\end{array}$ \\
\hline & DE & $\begin{array}{l}\text { Grundrechte in Leichte } \\
\text { Sprache } \\
\text { (Adaptación al alemán } \\
\text { del texto de los Derechos } \\
\text { fundamentales de las } \\
\text { personas) }\end{array}$ & $\begin{array}{l}\text { Alemania. La Asociación Netzwerk Leichte } \\
\text { Sprache cuenta con miembros en Alemania, } \\
\text { Austria, Italia, Suiza y Luxemburgo. Posee } \\
\text { un servicio de catálogo de libros, ofrece un } \\
\text { programa formativo y servicios de adaptación. } \\
\text { Otorga el sello de Lectura Fácil. } \\
\text { http://www.leichtesprache.org/ }\end{array}$ \\
\hline $\begin{array}{l}\text { Agencias de } \\
\text { servicios de } \\
\text { lectura fácil }\end{array}$ & DE & $\begin{array}{l}\text { Berliner Ratgeber für } \\
\text { Menschen mit Behinderung } \\
\text { in leichter Sprache } \\
\text { (Guía informativa para las } \\
\text { personas con discapacidad } \\
\text { en Lectura Fácil del estado } \\
\text { de Berlín) }\end{array}$ & $\begin{array}{l}\text { Alemania. Adaptación en formato Electrónico } \\
\text { (PDF) realizada por la agencia Leicht gesagt. La } \\
\text { guía contiene información sobre los servicios } \\
\text { ofrecidos por el estado de Berlín a las personas } \\
\text { con discapacidad. El cliente fue el Berliner } \\
\text { Senatsverwaltung für Gesundheit und Soziales } \\
\text { (Ministerio de Salud y Asuntos Sociales del } \\
\text { estado de Berlín). } \\
\text { www.leicht-gesagt.de }\end{array}$ \\
\hline
\end{tabular}

I I. Los ámbitos originales de la búsqueda incluían la documentación técnica, formación universitaria y los medios audiovisuales. Estas áreas de interés han tenido que excluirse por no haberse detectado proyectos.

I 2. Según los códigos internacionales incluidos en la norma ISO 3 I 66-I (Wikipedia 2016).

I3. Lebenshilfe es una asociación para la ayuda a personas con discapacidad intelectual, a sus familias y a profesionales y amigos. 


\begin{tabular}{|c|c|c|c|}
\hline Ámbito ${ }^{11}$ & Idioma $^{12}$ & Nombre del proyecto & País y descripción \\
\hline \multirow[t]{2}{*}{$\begin{array}{l}\text { Colecciones de } \\
\text { libros digitales }\end{array}$} & EN & Tar Heel Reader & $\begin{array}{l}\text { EE UU. Colección de libros en LF de acceso libre. } \\
\text { Gran variedad de temas. Accesible a través de } \\
\text { diversas interfaces. Permite contribuir redactando } \\
\text { o adaptando libros. } \\
\text { La herramienta ha sido creada por la Universidad } \\
\text { de Carolina del Norte. } \\
\text { http://tarheelreader.org/ }\end{array}$ \\
\hline & ES & Biblioteca Léelo Fácil & $\begin{array}{l}\text { España. Biblioteca de libros en castellano e } \\
\text { inglés. Lectura en línea o descarga. } \\
\text { http://www.leelofacil.org/ } \\
\text { El proyecto, iniciado por Confederación FEAPS } \\
\text { España, se realizó }{ }^{14} \text { con la editorial oneclick de } \\
\text { productos educativos digitales, que también ha } \\
\text { participado en el trabajo. } \\
\text { http://www.oneclick.es/ }\end{array}$ \\
\hline \multirow[t]{2}{*}{$\begin{array}{l}\text { Educación e } \\
\text { investigación }\end{array}$} & ES & $\begin{array}{l}\text { Creando caminos hacia } \\
\text { la educación de adultos } \\
\text { (Pathways) }\end{array}$ & $\begin{array}{l}\text { Bélgica. Participación española en el proyecto } \\
\text { europeo para aumentar las posibilidades de } \\
\text { las personas con discapacidad para recibir } \\
\text { formación para adultos mediante la traducción } \\
\text { y adaptación de las normas de Lectura Fácil } \\
\text { y de otros materiales de apoyo dirigidos a } \\
\text { profesionales del ámbito educativo. } \\
\text { http://easy-to-read.eu/es/ }\end{array}$ \\
\hline & ES & $\begin{array}{l}\text { Lenguaje figurativo y } \\
\text { anáforas en trastornos del } \\
\text { desarrollo: estudio de los } \\
\text { movimientos oculares }\end{array}$ & $\begin{array}{l}\text { España. Proyecto de investigación de la } \\
\text { Universidad de Valencia para contribuir a la } \\
\text { simplificación de textos tanto manual como } \\
\text { automática de forma que, en combinación con la } \\
\text { instrucción directa de los profesores, mejore el } \\
\text { rendimiento de los estudiantes. } \\
\text { http://www.uv.es/ }\end{array}$ \\
\hline \multirow[t]{4}{*}{$\begin{array}{l}\text { Tecnología, } \\
\text { navegación } \\
\text { en Internet y } \\
\text { herramientas }\end{array}$} & $\begin{array}{l}\text { DE, EN, } \\
\text { ES }\end{array}$ & Diccionario en línea Hurraki & $\begin{array}{l}\text { Alemania. Diccionario en línea de LF basado } \\
\text { en un wiki colaborativo. Patrocinado por el } \\
\text { Ministerio alemán de trabajo y asuntos sociales. } \\
\text { http://hurraki.de/wiki/Hauptseite }\end{array}$ \\
\hline & EN & Able to Include & $\begin{array}{l}\text { Bélgica. Proyecto europeo dedicado a fomentar } \\
\text { el uso y desarrollo de tecnología de apoyo para } \\
\text { favorecer el acceso de las personas con DI a los } \\
\text { medios sociales. } \\
\text { http://able-to-include.com/an-accessible-email/ }\end{array}$ \\
\hline & ES & Text to easy-to-read & $\begin{array}{l}\text { Bélgica. Proyecto integrante de Able to include } \\
\text { destinado al desarrollo de tecnología de apoyo } \\
\text { de simplificación de textos. } \\
\text { Utiliza el sistema automático de simplificación de } \\
\text { textos Simplext, proyecto que lideró Technosite, } \\
\text { la empresa tecnológica del grupo Fundosa. } \\
\text { http://able-to-include.com/accessible-services/ } \\
\text { services/text-to-easy-to-read }\end{array}$ \\
\hline & ES & $\begin{array}{l}\text { Diccionario Online Lectura } \\
\text { Fácil }\end{array}$ & $\begin{array}{l}\text { España. Proyecto liderado por Plena Inclusión } \\
\text { Madrid junto con la Fundación Repsol y } \\
\text { la Fundación del Español Urgente. Estará } \\
\text { disponible entre diciembre de } 2016 \text { y marzo de } \\
2017 . \\
\text { http://www.diccionariofacil.org/ }\end{array}$ \\
\hline
\end{tabular}

I4. Aunque ambos respondieron el cuestionario, se presenta como un proyecto único. 
Anexo III. Descripción de los proyectos

A continuación, se incluye información adicional sobre las asociaciones y las organizaciones que amablemente han participado en la parte empírica del trabajo y a los que deseo expresar mi máximo agradecimiento por su colaboración. Los datos aportados proceden en su mayoría de Internet y se amplían con datos recogidos durante la investigación.

Boletín para autogestores Europe for us!, ¡Europa para nosotros!

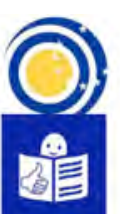

El boletín digital informativo ¡Europa para nosotros! es publicado por la Plataforma Europea de Autogestores, (EPSA, de sus siglas en inglés). Fundada en el año 2000. EPSA es parte de Inclusión

Europa (Inclusion Europe) y está compuesta por organizaciones de autogestores de diferentes países de Europa. Tal y como dice la plataforma en su página web: "Europa necesita más autogestores para ayudar a conseguir una vida mejor para las personas con discapacidad intelectual.”

Además de representar a grupos de autogestores en Europa, EPSA se encarga de:

- Comunicar a los líderes políticos las inquietudes, necesidades e intereses de los autogestores.

- Publicar información accesible sobre asuntos europeos importantes.

- Trabajar para reforzar el movimiento europeo de autogestores.

- Enseñar a los autogestores cómo pueden representarse a sí mismos.

- Organizar conferencias para intercambiar experiencias.

- Trabajar para dar a conocer la autogestión en toda Europa.

- Mantener una lista actualizada de organizaciones de autogestores.
- Publicar guías sobre temas que son de interés para los autogestores o que tienen que ver con la autogestión.

Para visitar la plataforma de la asociación, acceda a: http://inclusion-europe.eu/.

Inclusion Europe / Inclusión Europa

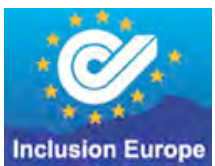

La Asociación Europea de Personas con Discapacidad Intelectual y sus Familias, Inclusión Europa, "representa la voz de personas con discapacidad intelectual y sus familias en toda Europa”.

Fundada en I988, Inclusión Europa lucha por la igualdad de derechos y la plena inclusión de las personas con discapacidad intelectual y sus familias en todos los aspectos de su vida. Cuatro de los proyectos incluidos han sido iniciativa de Inclusion Europe.

La asociación trabaja en numerosas áreas que sus miembros consideran de interés, tal y como indican ellos mismos:

- “A través de Inclusion Europe aprendí lo que hacen mis colegas en otros países".

- "Inclusion Europe ayuda a nuestra organización a ser más fuerte”.

- "Inclusion Europe conforma la política social europea de acuerdo a nuestras necesidades".

Inclusión Europa forma parte de Inclusion International, que es la organización mundial de personas con discapacidad intelectual y sus familias.

En Europa, Inclusion Europe es miembro del Foro Europeo de la Discapacidad (European Disability Forum, EDF), que es la asociación 
europea de personas con todo tipo de discapacidades y de la Plataforma Social (Social Platform), que es una red europea de organizaciones que trabajan en el terreno social. Ambas colaboran con Inclusion Europe en el desarrollo de las políticas sociales de la Unión Europea.

Para visitar el portal de la asociación, acceda a: http://inclusion-europe.eu/.

\section{Portal de noticias Klar Tale}



Klar Tale, Voz clara, es el único periódico en Lectura Fácil de Noruega. El periódico presenta la información maquetada, diseñada y redactada de forma que sea más fácil de leer que otros periódicos. El noticiero sale todos los jueves y ofrece información sobre temas nacionales, internacionales, culturales y deportivos.

Es posible suscribirse al periódico tanto en Noruega como en el extranjero y se publica tanto en papel como en formato audio y digital a través del portal.

Además de noticias, en http://www.klartale.no/ se publica semanalmente una tarea basada en un artículo de la versión impresa, que suele ser de especial interés para las escuelas.

Asimismo, cada dos jueves puede descargarse en el portal http://www.klartale.no/ el periódico Claro y Breve redactado en nynorsk ${ }^{15}$.

Por último, en http://nyheteribilder.no/, pueden leerse noticias redactadas en un lenguaje aún más fácil de leer gracias al uso de símbolos e imágenes. Este portal se actualiza también de forma semanal.

Para visitar el portal de noticias, acceda a: http://www.klartale.no/.

I 5. Uno de las dos formas escritas y oficiales del lenguaje noruego.

\section{Sidor}



El periódico sueco en Lectura Fácil 8 Sidor, 8 Páginas, se publica desde hace ya 30 años. El noticiero sale todos los miércoles y ofrece a sus lectores información sobre la actualidad nacional e internacional. La tirada del periódico es I I.০oo ejemplares, y cuenta con un número estimado de I00.000 lectores repartidos por todo el país.

Publicado por la Agencia para Medios Disponibles, MTM en sus siglas en sueco, el noticiero está financiado por el Ministerio de Cultura de Suecia y persigue garantizar que todas las personas con dificultades para leer tengan acceso a la información. Además del periódico, MTM se dedica al desarrollo y la investigación de tecnologías para la lectura. Para visitar el portal de noticias, acceda a: http://8sidor.se/.

Leichte Sprache in der Landesverwaltung, Baden-Wurttemberg

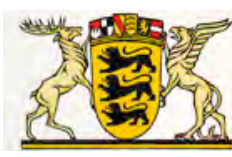

Lectura Fácil en la Administración del Estado Federado de Baden-Wurttemberg es un proyecto de un año de duración financiado por el gobierno dentro del marco de medidas de implantación de la Convención de los Derechos de las Personas con Discapacidad.

El proyecto persigue sensibilizar y apoyar a la administración del gobierno de este estado federado en la producción de información en lectura fácil. Durante el proyecto se creará una guía para los empleados de la administración con pautas de redacción. Asimismo, se pondrá a disposición de la administración la posibilidad de adquirir derechos de acceso a una base de datos de símbolos. 
Aunque el proyecto no cuenta con sitio web propio, en la siguiente página puede obtenerse información en lectura fácil sobre el gobierno de Baden Wurttemberg:

http://www.baden-wuerttemberg.de/de/headerund-footer/leichte-sprache/.

\section{Netzwerk Leichte Sprache}

\section{* Nekzwerk \\ $\triangle$ Leichte Sprache}

Desde su fundación en $\mathbf{2 0 0 6}$, la asociación alemana Netzwerk Leichte Sprache dedica sus esfuerzos a convertir en accesible la información de forma que todas las personas puedan disfrutar de ella. La asociación cuenta con miembros en Alemania, Austria, Italia, Suiza y Luxemburgo.

La organización posee un servicio de catálogo de libros, ofrece un programa formativo, servicios de adaptación, traducción y validación de textos, y realiza trabajo de difusión y concienciación a través de talleres y ponencias. Asimismo, la asociación otorga el sello de lectura fácil.

Para visitar la página de la asociación, acceda a: http://leichtesprache.org/.

\section{Berliner Ratgeber für Menschen mit} Behinderung in leichter Sprache

(Guía informativa para las personas con discapacidad en lectura fácil del estado de Berlín).

\section{leicht gesagt}

\section{Agentur für leichte Sprache}

La agencia alemana leicht gesagt fue fundada en 2010 por Gabriele Hiller, especialista en márketing y comunicación. La agencia ofrece servicios de creación, traducción, maquetación y complemento con imágenes, así como de gestión integral de proyectos de lectura fácil.
Gracias a una amplia red de proveedores y especialistas externos, la agencia forma equipos de trabajo multidisciplinares según las necesidades de cada proyecto.

La agencia trabaja con organizaciones regionales, como Lebenshilfe, en la validación de los textos y documentos para asegurar su comprensibilidad.

Para visitar la página de leicht gesagt, acceda a: http://www.leicht-gesagt.de/Hauptseite.html.

\section{Tar Heel Reader}

\section{Tar Heel Reader}

La biblioteca de libre acceso Tar Heel Reader es un servicio ofrecido por el Centro de Estudios de Alfabetización y Discapacidad de la Universidad de Carolina de Norte, en Chapel Hill (EE UU). El desarrollo de esta herramienta ha sido posible gracias al trabajo del Departamento de Ciencias de la Computación de la misma universidad.

La herramienta permite acceder de forma gratuita por Internet a libros en muy diversos ámbitos e idiomas a través de múltiples interfaces como pantallas táctiles, teclados de conceptos, interruptores, etcétera. Asimismo, permite crear libros propios incorporando imágenes de Flickr o propias.

Con libros para adolescentes y adultos, y libros para lectores principiantes jóvenes, Tar Heel lector persigue contribuir a abordar el problema de la alfabetización y el acceso a la información de alumnos con problemas de aprendizaje o de lectura de todas las edades.

Para visitar la página de Tar Heel Reader, acceda a: http://tarheelreader.org/. 


\section{Biblioteca Léelo Fácil}

\section{Léelo $\mathbf{a}$ fácil \\ PPlena inclusión \\ Plena inclusión España}

La biblioteca Léelo Fácil es un proyecto de la asociación Plena inclusión, que representa en España a las personas con discapacidad intelectual o del desarrollo.

Desde hace más de 50 años, la asociación contribuye a la plena inclusión de estas personas y de sus familias en la sociedad y defiende sus derechos.

Plena inclusión está formada por I 7 federaciones autonómicas y casi 900 asociaciones en toda España.

La misión de Plena inclusión es "contribuir, desde su compromiso ético, con apoyos y oportunidades, a que cada persona con discapacidad intelectual o del desarrollo y su familia puedan desarrollar su proyecto de calidad de vida, así como a promover su inclusión como ciudadana de pleno derecho en una sociedad justa y solidaria”.

La biblioteca Léelo Fácil es una página web libre y gratuita que permite leer en línea libros adaptados en lectura fácil, diseñados con dibujos, música y animaciones para mejorar su comprensibilidad. Los libros están disponibles en castellano e inglés.

La web ha sido realizada dentro del marco del proyecto de FEAPS LÉELO FÁCIL 2.0, que subvenciona el Ministerio de Educación, Cultura y Deporte.

Para visitar la página de Léelo Fácil, acceda a: http://www.leelofacil.org/.

Para visitar la página de Plena Inclusión, acceda a: http://www.plenainclusion.org/.

\section{Editorial oneclick}

\section{oneclick}

La editorial oneclick es un proveedor de referencia de servicios digitales. oneclick ofrece soluciones formativas que marcan la diferencia. La gama de productos incluye libros digitales, simuladores formativos, videojuegos educativos y servicios de consultoría.

onclick trabaja con Plena Inclusión en el proyecto Léelo Fácil.

Para visitar la página de oneclick, acceda a: http://www.oneclick.es/.

\section{Creando caminos hacia la educación de adultos (Pathways)}



Plena Inclusión participó en este proyecto europeo destinado a que las personas con discapacidad tengan más posibilidades de recibir formación para adultos.

Como resultado del proyecto se crearon cuatro guías en lectura fácil y un curso para formar a otras personas sobre cómo hacer materiales en lectura fácil.

Las guías son: Información para todos, que recoge las normas para hacer escritos en LF, la guía ¡No escribas para nosotros sin nosotros!, que presenta cómo hacer que las personas con discapacidad intelectual participen en la elaboración de escritos en lectura fácil, la guía Enseñando a profesores de educación de adultos, diseñada para enseñar a organizar un curso para crear escritos en lectura fácil, y la guía Enseñar puede ser fácil, pensada para que los profesores aprendan a organizar cursos para personas con discapacidad intelectual.

Para descargar las guías, acceda a: http://www. plenainclusion.org/informate/publicaciones. 


\section{Lenguaje figurativo y anáforas en trastornos del desarrollo: estudio de los movimientos oculares}

(10) VNIVERSITAT
DQ̈VALENCIA

El objetivo de este proyecto de investigación es evaluar la influencia del lenguaje figurativo y de los elementos anafóricos en la comprensión lectora de diversos tipos de trastornos del desarrollo, en particular, los trastornos del espectro autista (TEA) y la discapacidad intelectual (DI).

La influencia de estos factores se medirá tanto a través de la comprensión offline (respuestas a preguntas tras la lectura del texto) como online (mediante el registro de movimientos oculares durante la lectura).

Los resultados del estudio pretenden contribuir al desarrollo de técnicas manuales y automáticas de simplificación de textos usadas en el contexto educativo en combinación con la instrucción directa de forma que supongan una mejora del rendimiento de estudiantes con estas dificultades.

\section{Diccionario en línea Hurraki}

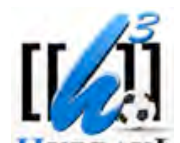

El diccionario de lectura fácil Hurraki ha sido creado por Hep Hep Hurra, Alemania.

Se trata de un diccionario colaborativo basado en un sistema wiki. El objetivo perseguido es volver accesible la información para todas las personas y fomentar así la inclusión.

La herramienta permite el acceso y la edición a todas las personas que deseen contribuir. Actualmente, las búsquedas pueden realizarse en alemán, español e inglés.

Para visitar la página de Hurraki, acceda a: http://hurraki.org/.

\section{Able to Include}

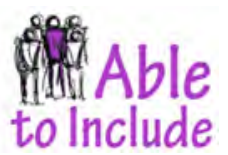

Able to Include es un proyecto financiado dentro del Programa Marco de Competitividad e Innovación (CIP PSP, en sus siglas en inglés).

El proyecto persigue mejorar la calidad de vida de las personas con discapacidad intelectual o del desarrollo, así como de aquellas con condiciones similares, como las personas afectadas por la demencia o cualquier tipo de deterioro cognitivo. Para lograrlo, el proyecto integra un conjunto de tecnologías ya desarrolladas para crear una capa de accesibilidad sensible al contexto que, al integrarse en herramientas TIC, existentes y futuras, puede mejorar la vida diaria de las personas con DI al facilitar la comprensión de su entorno, y ayudarles a interactuar con la sociedad de la información. El proyecto se centra en las áreas más importantes que una persona necesita para vivir de forma independiente: socializar en el contexto de la web 2.0, viajar de forma independiente y ser capaz de trabajar.

Tres tecnologías clave se utilizan como marco para desarrollar las tareas cotidianas:

- Text2Picto: traductor de texto a pictogramas.

- $\quad$ Simplext / Text to Easy-to-Read: simplificador de textos.

- Text to speech: conversor de texto a voz.

Para visitar la página de Able to Include, acceda a: http://able-to-include.com/.

\section{Diccionario Lectura Fácil}



Plena Inclusión Madrid, antes FEAPS Madrid, es la federación de organizaciones de personas con discapacidad intelectual o del desarrollo de Madrid. 
Es una entidad sin ánimo de lucro que nació en Madrid en el año I978 y cuya acción se traduce en proveer servicios, defender derechos y ser agente de cambio social. Representa al movimiento asociativo de la discapacidad intelectual en la Comunidad de Madrid.

El objetivo es crear un diccionario en línea de términos definidos en lectura fácil, destinado a que personas con discapacidad intelectual en particular y a cualquier otro sector de la población con dificultades de comprensión lectora puedan entender mejor la información.

Para ello, se ha definido un proceso de trabajo en el que intervienen hasta cinco agentes diferentes en la adaptación y validación de cada término (productores de lectura fácil, validadores de lectura fácil e imágenes de apoyo) y lingüistas, y que cuenta con una herramienta informática de gestión de flujos de trabajo y trabajo en red.

La página web que hará pública la base de datos de términos estará disponible entre diciembre de 2016 y marzo de 2017.

El proyecto cuenta con la colaboración de Fundación Repsol y de la Fundación del Español Urgente Fundéu BBVA.

En la validación de textos participan Adisli, Apama, Aspacén, Fundación Ademo, Fundación Aprocor y Grupo AMÁS.

La información se ha obtenido de la página: http://www.plenainclusionmadrid.org/proyecto/ diccionario-lectura-facil/. 